\title{
Big accents in Stockholm Swedish: Nuclear accents, prenuclear accents, and initiality accents
}

\section{Glossa}

a journal of general linguistics
SARA MYRBERG (1)

\begin{abstract}
Stockholm Swedish has a distinction between so-called big accents and small accents (in addition to a lexical contrast between tone accent 1 and tone accent 2). The function and distribution of the big versus small accent has never been fully understood. West Germanic languages lack a corresponding distinction. While it is known that big accents appear on information-structural focus, this fact cannot account for all big accents, nor can it explain the existence of the big accent in relation to the domains of the prosodic hierarchy. In this article, the distribution of big accents in preverbal subjects is studied. A production study is presented where native speakers read sentences with preverbal subjects of four different lengths, with or without information-structural focus. Based on the results, it is argued that heads of prosodic phrases $(\varphi)$ serve as hosts of big accents (one and only one big accent per $\varphi$ ). The rightmost big accent in the intonation phrase ( 1 ) is referred to as the nuclear accent, and all other (nonrightmost) big accents are referred to as prenuclear accents. Heads of $\varphi$ are aligned with the right edge of $\varphi$ by default. However, the leftmost $\varphi$ inside an I may (nonobligatorily) be left-headed, causing a big accent to appear at the leftmost prosodic word $(\omega)$ of I. Such left-aligned prenuclear accents are referred to as initiality accents. These assumptions regarding the big accent in Stockholm Swedish account for the large observed variation in terms of big accent distribution in the preverbal subjects.
\end{abstract}

\section{] $\mathrm{u}[$ ubiquity press}

\author{
RESEARCH
}

CORRESPONDING AUTHOR:

\section{Sara Myrberg}

Centre for Languages

and Literature, SOL, Lund

University, SE-221 00 Lund, GB

sara.myrberg@nordlund.lu.se

\section{KEYWORDS:}

big accent; initiality accent; Stockholm Swedish; syntaxprosody interface; prosodic phrase

TO CITE THIS ARTICLE: Myrberg, Sara. 2021. Big accents in Stockholm Swedish: Nuclear accents, prenuclear accents, and initiality accents. Glossa: a journal of general linguistics 6(1): 81. 1-28. DOI: https://doi.org/10.5334/ gjgl.1227 


\section{Introduction}

It has been known (at least) since Gösta Bruce's seminal thesis (Bruce 1977) that Stockholm Swedish has a distinction between two tonally distinct types of pitch accents, tied to perceptually strong versus weak prominence. Henceforth, these will be referred to as big accents and small accents respectively. ${ }^{1}$

The distinction between big and small accent has received rather extensive attention in the literature, and by now, it seems clear that it has no direct parallel in any of the West Germanic languages (among others Bruce 1977; 1982; 1987; 1998; 2005; 2007; 2010; Bruce, Granström, Gustafson \& House 1993; Gussenhoven \& Bruce 1999; Heldner 2001; Hansson 2003; Gussenhoven 2004; Ambrazaitis 2009; Myrberg 2010; 2013b; Myrberg \& Riad 2015; 2016). In spite of the attention, the distinction between big and small accent in the intonation system of Scandinavian dialects cannot be said to be fully understood.

The main topic of the current article is the big accent. No previous analysis has provided a complete account of the existing types or functions of big accents. The big accent has often been referred to as a focus accent, as it appears on focus with very few exceptions. ${ }^{2}$ However, by now, it is clear that there is no one-to-one correspondence between information-structural focus and big accents (Myrberg 2010; Myrberg \& Riad 2015; 2016). Big accents regularly occur on given material, and focused material can contain more than one big accent (as will be shown in this study). In addition, it has been observed that the big accent contour appears regularly as a phrasing cue at some types of left edges, here referred to as initiality accents (Horne 1994; Roll, Horne \& Lindgren 2009; Myrberg 2010; 2013b).

Therefore, information-structural focus alone cannot explain the distribution or presence of big accents in the phonology of Swedish. The lack of empirical knowledge regarding the distributional patterns of big accents has been an obstacle for the understanding of the prosodic hierarchy in Swedish, specifically for the understanding of the prosodic phrase $(\varphi)$ in relation to the intonation phrase (l) (cf., Myrberg 2010; 2013b; Myrberg \& Riad 2015).

The prosodic hierarchy is a set of hierarchically organized prosodic domain types, which are defined exclusively in phonology, and are independent from constituents in syntax (but which are often aligned with syntactic constituent types). In the present article, the architecture of the prosodic hierarchy developed by Itô and Mester (2012), and applied to Stockholm Swedish by Myrberg and Riad (2015), is assumed. This hierarchy includes three domain types: the prosodic word $(\omega)$, the prosodic phrase $(\varphi)$ and the intonation phrase $(\mathrm{l})$ and is further explained in Section 2.2. See also Section 2.4 for a discussion on the basic assumptions regarding the interface between syntax and prosody.

The analysis of big accents presented here is based on the results of a production experiment using sentences with clause-initial noun phrase subjects. Clause-initial constituents are particularly instructive for the study of big accents, as they reveal the nature of a) the relation between big and small accents, b) the relation between initiality accents and other big accents, c) the relation between nuclear big accents and non-nuclear big accents, as well as d) the distribution of big accents in relation to syntactic phrases (XPs). Native speakers of Stockholm Swedish read sentences shown to them on a computer screen. Subject length and location of information-structural focus were systematically varied.

The results shed light on the distributional patterns of big accents and provide the base for a coherent analysis of the different functions of big accents in Swedish. The results support a division of big accents into nuclear versus prenuclear. Further, prenuclear big accents can be divided into right-aligned (default) and left-aligned (referred to here as initiality accent, following Myrberg 2010; 2013b; Myrberg \& Riad 2015).

Moreover, the results contribute to a deeper understanding of the $\varphi$ and its interface with syntax in Stockholm Swedish. Empirical evidence for a distinction between $\varphi$ and $\mathrm{\iota}$ is also provided. The large amount of variation in the data can be understood under the assumption that all big accents are heads of one $\varphi$. The nuclear accent is also the head of an intonation phrase ı (by

1 In previous research the terms focus accents and word accent have often been used, see Section 2.1.

2 The small accent has been assumed to be related to the tone accent distinction in Swedish and Norwegian (e.g., Bruce 1977). See discussion and references in Sections 2 and 2.1. 
projection of the rightmost big accent inside $\mathrm{l}$ ). The main claims regarding big accent types and their positions in the prosodic hierarchy of Stockholm Swedish are summarized in Table 1.

\begin{tabular}{|c|c|c|}
\hline & prenuclear big accents & nuclear big accents \\
\hline definition & all non-rightmost big accents in I & rightmost big accent in I \\
\hline headedness & head of $\varphi$ & head of I \\
\hline function & $\begin{array}{l}\text { primarily phrasing function, no correlation } \\
\text { with information-structural focus }\end{array}$ & $\begin{array}{l}\text { correlation with information-structural } \\
\text { focus }\end{array}$ \\
\hline alignment & $\begin{array}{ll}\text { left-aligned in } \varphi & \text { right-aligned in } \varphi \\
\text { (initiality accent) } & \text { (default) }\end{array}$ & right-aligned in I \\
\hline
\end{tabular}

Table 1 The types of big accents and their primary functions in Stockholm Swedish. Tonal representations for big accents are provided in Table 2.

The claims summarized in Table 1 are based on analysis of the substantial amount of optionality in the alignment between syntax and prosody, which is evidenced by the results. A summary of the most common phrasing options in preverbal NP subjects is provided in (1). Examples (1a)-(1c) represent subjects phrased in a single $\varphi$. Examples $d-g$ represent subjects phrased in two $\varphi$ 's.

(1) Possible prosodic structures for information-structurally given, preverbal subjects consisting of two XPs. Round brackets represent $\varphi$-edges. Curly brackets represent t-edges. Bold represents prenuclear big accents. Small caps represents nuclear big accents.

$$
\begin{aligned}
& { }_{\mathrm{CP}}\left[{ }_{\text {Subj }}\left[{ }_{\mathrm{XP}}[\text { Den bruna haren }]_{\mathrm{XP}}{ }_{\mathrm{XP}}[\text { med söta ungar }]_{\mathrm{XP}}\right]_{\text {Subj }} \text { bor }[\mathrm{i}\right. \\
& \text { parken. } \left.]_{\text {Focus }}\right]_{\mathrm{CP}} \\
& \text { the brown hare with cute kids lives in }
\end{aligned}
$$

park.the

'The brown hare with cute kids lives in the park.'
a. \{( Den bruna haren med söta ungar ) ( bor i PARKEN.) \}
b. \{ ( Den bruna haren med söta ungar ) ( bor i PARKEN.) \}
c. $*\{$ ( Den bruna haren med söta ungar bor i PARKEN.) $\}$
d. \{ ( Den bruna haren ) ( med söta ungar ) ( bor i PARKEN.) \}
e. \{ ( Den bruna haren ) ( med söta ungar ) ( bor i PARKEN.) \}
f. \{ ( Den bruna haren ) ( med söta ungar ) ( bor i PARKEN.) \}
g. $*\{$ ( Den bruna haren ) ( med söta ungar ) ( bor i PARKEN.) $\}$

First, (1) supports the need for a distinction between nuclear big accents and prenuclear big accents in Stockholm Swedish (see further Sections 2.2 and 5.1). This argument is based on the observation that there are frequently multiple big accents inside the subject (cf., (1d)-(1f), and Sections 4.2, 4.3). Each big accent is head of one $\varphi$ (Table 1). The nuclear versus prenuclear distinction accounts for the fact that the big accents in a sentence have different functions. The rightmost, nuclear, big accent correlates with information-structural focus, whereas prenuclear big accents primarily have a phrasing function. Myrberg (2010) and Myrberg and Riad (2015) hypothesized that a distinction between nuclear and prenuclear big accents would be necessary for Swedish, as for other Germanic languages, but no strong empirical support for this assumption was provided in these publications. Earlier models of Swedish intonation have made no distinction between nuclear and prenuclear big accents, nor have any strong assumptions been made regarding the relation between prosodic edges and big accents (see discussion in Hansson 2003). It can be noted already here that a larger number of prenuclear big accents in the subject is more common with long subjects, which contain more than one syntactic XP. This is entirely expected under current theories of the alignment between syntax and prosody, which predict a general tendency to put a $\varphi$-head in each syntactic XP (e.g., Truckenbrodt 1999; Féry \& Samek-Lodovici 2006; Selkirk 2011; Itô \& Mester 2012).

Second, the variation in (1) illustrates that the preverbal constituent obligatorily contains (at least) one big accent ( $\varphi$-head), as evidenced by the absence of structures like (1c). ${ }^{3}$ This supports 
the assumption that the preverbal constituent, i.e., the constituent inside Spec-CP, is obligatorily separated from the rest of the clause by a $\varphi$-break (see also Section 5.3). The obligatory big accent may be aligned either with the left edge of the $\varphi$ as in (1a) (initiality accent), or with the right edge of the $\varphi$ as in (1b). It can be noted that in subjects with two prenuclear accents, the left one may be left-aligned (1f), or both may be left-aligned (1d). However, a medial big accent alone may not be left-aligned $(1 \mathrm{~g})$. We will return to this alternation regarding the location of $\varphi$-heads below.

The introduction of left-aligned $\varphi$-heads (1a) into the prosodic system of Swedish means that the previously described initiality accent (Roll, Horne \& Lindgren 2009; Myrberg 2010; 2013b) is analysed here as a left-aligned head of $\varphi$. This will be referred to here as the head analysis. While left-aligned heads are exotic in the Germanic languages, the head analysis fares better than either of the previous lines of analysis offered in the literature. The prominence analysis (Myrberg 2010; 2013b) leaves the initiality accent with an unsatisfactorily unclear status in relation to the prosodic hierarchy, and the boundary tone analysis (Roll, Horne \& Lindgren 2009) fails to account for the distribution of initiality accents, as discussed in Section 5.2.

The article is structured as follows. Section 2 provides a background to big and small accents, discusses the terminology, 2.1, and introduces the most important issues for which the results have implications: the separation between nuclear and prenuclear big accents, 2.2, and the phonological status of the initiality accent, 2.3. A short review of some basic assumptions regarding the syntax-prosody interface is also provided, 2.4. Section 3 presents the experimental design and data analysis procedure.

Section 4 presents the results. Section 4.1 describes subjects with one big accent (1a)-(1b), Section 4.2 describes subjects with two big accents (1d)-(1g), and Section 4.3 describes subjects with three big accents (less common and therefore not represented in (1)).

Section 5 discusses the implications of the results for the prosodic structure of Swedish. Section 5.1 explains in more detail the argument that a separation between $\varphi$ and $\iota$ is necessary for Swedish. Section 5.2 discusses the status of the initiality accent as a $\varphi$-head and develops the argument in favour of this claim. Section 5.3 presents an outlook to some further evidence regarding the phrasing of constituents inside Spec-CP, providing a view on how the analysis of the experimental results fit in to a bigger picture of Swedish prosodic structure. Section 6 concludes the paper.

\section{Tonal representations in Stockholm Swedish}

The prominence contours of Stockholm Swedish are shown in Table 2. Stockholm Swedish has a lexical distinction between two tone accents, usually referred to as tone accent 1 and 2 (alternatively acute and grave accent, respectively). These are represented in the two rows of Table 1. The two columns named small and big accent, respectively, refer to the two types of accents in Stockholm Swedish. ${ }^{4}$

\begin{tabular}{lll}
\hline & small accent & big accent \\
\hline tone accent 1 & $\mathrm{HL}^{*}$ & $\mathrm{~L}^{*} \mathrm{H}$ \\
\hline tone accent 2 & $\mathrm{H}^{*} \mathrm{~L}$ & $\mathrm{H}^{*} \mathrm{LH}$ (simplex words) \\
& & $\mathrm{H}^{*} \mathrm{~L}^{*} \mathrm{H}$ (compounds + many derivations) \\
\hline
\end{tabular}

As seen in Table 2, there are three different tonal representations for big accents in Stockholm Swedish: the simplex tone accent $1 \mathrm{~L} * \mathrm{H}$ contour (2a), the simplex tone accent $2 \mathrm{H} * \mathrm{LH}$ contour (2b) and the compound tone accent 2 contour $\mathrm{H}^{*} \mathrm{~L} * \mathrm{H}(2 \mathrm{c})$. All compounds have tone accent 2 in this dialect, and there is thus no tone accent distinction in compound structures. The compound

4 In Bruce's original work, the small accent tonal fall (early or late timed depending on the tone accent of the word) constitutes a subset of the big accent contour. A H-tone, sometimes referred to as the focal $H$, is added to the small accent fall to create the big accent. Bruce's idea that the big accent is composed of lexical + postlexical tones is not immediately represented in Table 1, but is nonetheless tacitly assumed throughout this paper. It should be pointed out that for the big accent contour in tone accent 1 , here $\mathrm{L}^{*} \mathrm{H}$, Bruces original work assumed an additional $\mathrm{H}$ tone, i.e., $\mathrm{HL}^{*} \mathrm{H}$. The existence of this tone has been disputed in the literature, and the issue of its existence will be left aside here, pending future empirical and theoretical research.

$$
\text { (1) }
$$


tone accent 2 contour differs from other tone accent 2 contours in having two association points, causing the two $\mathrm{H}$ tones to appear on the leftmost and the rightmost lexical stresses in a complex word, as in (2c). ${ }^{5}$ It is worth noting that a rather large set of derivational morphemes behave prosodically like stressed root morphemes. Words that contain this type of morpheme behave like compounds in terms of their tonal structure, and thus receive the $\mathrm{H}^{*} \mathrm{~L} * \mathrm{H}$ contour (Riad 2006; 2012; 2014).

Big accents in tone accent 1 simplex (a), tone accent 2 simplex (b) and tone accent 2 compound (c).

a. 'cirkusen 'the circus' trisyllabic tone accent 1 simplex $\mathrm{L} * \mathrm{H}$

b. 'sommaren 'the summer' trisyllabic tone accent 2 simplex $\mathrm{H} * \mathrm{LH}$

c. 'sommar,lov 'summer holiday' trisyllabic tone accent 2 compound $\mathrm{H}^{*} \quad \mathrm{~L}^{*} \mathrm{H}$

The big accent coexists in the intonation system with the small accent, from which it has generally been assumed to be categorically distinct. The categorical distinction is reflected in the wide consensus around two separate tonal representations for the accent types, as is also the case in Table 1 (cf., Bruce 1977; 1998 et seq; Heldner 2001; Hansson 2003; Ambrazaitis 2009; Myrberg 2010; 2013b; Myrberg \& Riad 2015).

Small accents are not the main topic of the current article. Nonetheless, they are relevant for the definition of the $\omega$ in Swedish. Riad (2014; 2015) and Myrberg \& Riad (2015), divide the $\omega$ in Swedish into a minimal and a maximal $\omega$ (cf., Itô \& Mester 2012). The minimal $\omega$ contains one and only one lexically stressed syllable, whereas the maximal $\omega$ contains one and only one small accent (or, by projection of the $\omega$ to head of $\varphi$, one big accent). In this article, the symbol $\omega$ will be used to refer to the maximal projection of the $\omega$, i.e., representing a prosodic domain which contains a single small or big accent (any of the five contours in Table 1).

\subsection{The terms big accent and small accent}

The frequently used pair of terms focus accent and word accent brings with it a number of problems which will become very prominent in the present discussion. Therefore, these terms are replaced here, with the pair of terms big accent and small accent, following Myrberg \& Riad (2015). Thus, what has previously been referred to as focus accent is termed big accent here, and what has been termed word accent is termed small accent.

The primary problem with the term pair focus accent and word accent is that it fails to separate the phonological form of an accent from its function. The term focus accent implies that this accent signals focus, and the term word accent implies that this accent expresses the lexical tone accent distinction. However, there is no one-to-one correlation between focus and big accents (a word may carry a big accent even though it is not focused). There is also not a one-toone correlation between the lexical tone accent distinction and the distribution of small accents (a word may be specified for tone accent 2 but still be realized without a small accent). The lack of a one-to-one correlation between big accents and information-structural focus creates a need to speak of the accent as an object separate from the information-structural status of the constituent on which the accent appears. Likewise, there is sometimes a need to speak separately of the lexical tone accent marking of a morpheme and the pitch accent that appears on a word in a specific realization.

5 Here, the difference in tonal behavior between simplex and complex words is represented by the additional * in the compound contour. An alternative, and perhaps more economical, analysis would be that there is only one tonal contour, which behaves differently in simplex and complex words because of the additional lexical stress(es) in the compound structures. 
Further complicating the picture, different dialects of Swedish and Norwegian have different tonal representations for the big and small accent, meaning that the terms should also not be too tightly tied to the specific shape of the contour. The terms small and big accent will allow cross-dialectal discussion of the accent types.

\subsection{The prosodic phrase $\varphi$ and the intonation phrase I in Stockholm Swedish}

Following Itô \& Mester (2012), three universal categories of the prosodic hierarchy will be assumed here: the prosodic word $\omega$, the prosodic phrase $\varphi$, and the intonation phrase $1 .{ }^{6}$ A fuller discussion and application of this model to Stockholm Swedish can be found in Myrberg $\&$ Riad (2015). For the discussion in this article, the most relevant domains will be the $\varphi$ and the $\mathrm{t}$. Sections 4 and 5 will present evidence that these two categories need to be distinguished for Stockholm Swedish. While such a distinction was also assumed for Swedish by Myrberg (2010; 2013) and Myrberg \& Riad (2014; 2015), the empirical evidence presented in these publications was not extensive.

An important part of the argument for a separation between the $\varphi$ and the $\mathrm{t}$ regards the existence of two separate prominence types, each of which serves as the head of one prosodic category. I will argue here that such a separation is necessary within the group of big accents, meaning that the prenuclear area may contain big as well as small accents (i.e., it is not the case that all prenuclear accents are small and all nuclear accents are big).

Nuclear accents are heads of $\mathrm{l}$ (the rightmost big accent in $\mathrm{l}$ ), and have a similar distribution in Swedish to that described for West Germanic languages like English, German and Dutch (Pierrehumbert 1980; Selkirk 1984; Féry 1993; Selkirk 1995; Gussenhoven 2004; Féry \& Samek-Lodovici 2006; Ladd 2008). As in other Germanic languages, information-structural foci obligatorily contain the nuclear accent, which is the rightmost and strongest prominence in Swedish sentences (Myrberg 2010; Myrberg \& Riad 2015; 2016). ${ }^{7}$ In Swedish, like in other Germanic languages, the requirement that a focus must contain the nuclear accent results in a ban on strong prominences in the postfocal area (e.g., Selkirk 1984; Ladd 2008; Féry 2013). In Swedish, this means that there are no big accents in postfocal areas (note, however, that small accents are realized postfocally in the Stockholm variety of Swedish, cf., discussion in Hansson 2003; Bruce 2007; Myrberg 2010).

Prenuclear big accents are heads of $\varphi$ and there may be several prenuclear big accents inside one ı. From the perspective of the literature on West Germanic languages, where prenuclear pitch accents are relatively well described, and where there are frequently multiple pitch accents inside a sentence, the need for a distinction between nuclear and prenuclear big accents might seem somewhat trivial. In the Swedish literature, however, it is far from obvious that big accents can appear alongside small accents in prenuclear position. Earlier accounts of Swedish prosodic structure belonging to the so-called Lund-model of Swedish intonation made no distinction between nuclear and pre-nuclear prominences, beyond the separation between small and big accents (cf., e.g., Bruce 1982; 1998; Heldner 2001; Hansson 2003). Hansson (2003) makes a thorough review of the known facts about the domains in the prosodic hierarchy of Swedish, and reaches the conclusion that only one category above the $\omega$ can be supported. In the Swedish literature, the big accent has been strongly associated with the expression of focus, and in the seminal work by Bruce (1977) it was referred to as a sentence accent, capturing the observation that (almost) all utterances must have at least one big accent. In most subsequent literature, the big accent has been referred to as focus accent, indicating that signalling of focus is its primary function (e.g., Bruce 1987; 1998; Gussenhoven \& Bruce 1999; Heldner 2001; Hansson 2003; Gussenhoven 2004; Bruce 2007; Ambrazaitis 2009; Roll, Horne \& Lindgren 2009; Myrberg 2013b). The conception of big accents as focus accents or sentence accents implies that the big accent should bear some correlation with what in the West Germanic literature has been referred to as the "nuclear accent", i.e., the rightmost and

6 It can be noted that no category utterance is assumed here, following Itô \& Mester (2012), where the utterance from some earlier models (e.g., Nespor \& Vogel 1986) corresponds to the highest, maximal, projection of the $\mathrm{t}, \mathrm{\iota}^{\max }$. See Myrberg (2010; 2013) Myrberg \& Riad (2015) for more extensive discussion of Itô \& Mester's model applied to Swedish. See also Hansson 2003: 161 for an argument against the utterance as a separate category in the prosodic hierarchy of Swedish.

$7 \quad$ Nuclear accents are in principle always big accents, but see Ambrazaitis (2009) and Myrberg (2010) for a small number of exceptions. 
most prominent accent in a sentence, which also correlates with the focus of the sentence. Under this conception, there should, in most cases, be one big accent per sentence (or per focus domain, which would correlate with the sentence in simple cases like those presented here, cf., discussion by e.g., Truckenbrodt 1995; Féry \& Samek-Lodovici 2006). The results from the experiment presented here, however, will give ample evidence that there are frequently more than one big accent per sentence in Stockholm Swedish.

\subsection{Initiality accent}

In addition to appearing on focused items as described in the previous section, big accents have been observed to appear at the left edges of phrases, i.e., phrase-initially. In this position, they function as a phrasing cue (Horne 1994; Roll 2006; Roll, Horne \& Lindgren 2009; Myrberg 2010; 2013b; Söderström 2017). These big accents will be referred to here as initiality accents, following Myrberg (2010; 2013b).

The initiality accent appears on the leftmost $\omega$ in (the leftmost $\varphi$ of) an $\iota^{8}{ }^{8}$ The requirement on $\omega$-status means that almost all content words in the relevant position obligatorily receive initiality accent, whereas function words, such as pronouns and articles, are often not eligible for initiality accent (see Section 5.2, Figure 20).

An example of an initiality accent is provided in Figure 1 where the initial word många 'many' carries the initiality accent. Note that the right $\mathrm{H}$ tone of this accent is realized very late, on the initial syllable of rostiga 'rusty'. This late timing is typical of initiality accents, and separates the tonal behaviour of the initiality accent from other big accents (Roll, Horne \& Lindgren 2009; Myrberg 2010). The late timing is, however, not obligatory, as illustrated by the initiality accent on dåliga 'bad' in Figure 2. When appearing on a compound, the second rise begins on the secondary stress, in parallel with other big accents on compounds, (2c) and Figure 3.
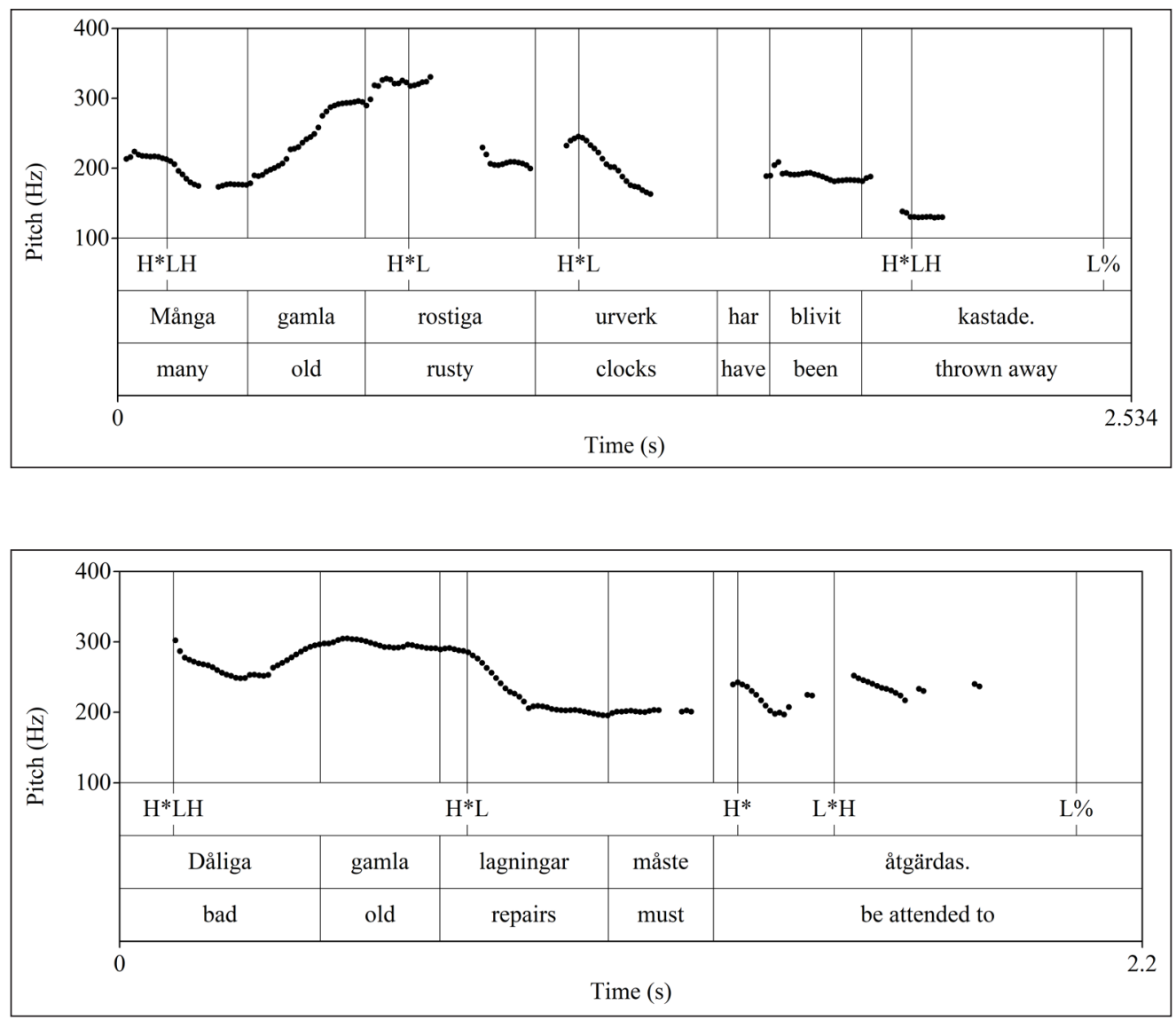

8 In later sections of the article it will be shown that left-aligned heads may also appear inside the second left-aligned $\varphi$-heads of an $\mathrm{t}$, but only if the first $\varphi$ also has a left-aligned head, cf., (1d) versus (1g). All left-aligned heads will be referred to as initiality accents, meaning that these terms are essentially synonymous.
Figure 1 Initiality accent with late timing. Adapted from Myrberg (2010: 57).

Figure 2 Initiality accent with early timing. Adapted from Myrberg (2010: 54). 


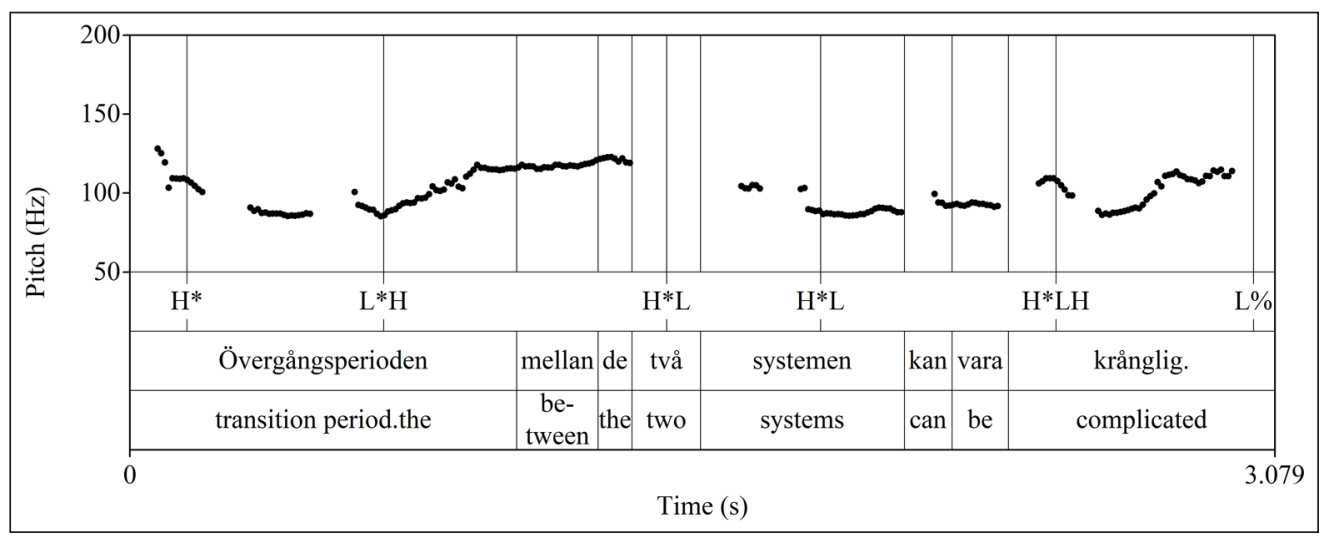

Initiality accents frequently appear in the results of the experiment presented in this article. In (1), big accents which appear on the words bruna or många are initiality accents, because they appear on the leftmost $\omega$ in their $\varphi$, cf., (1a, d, f). As mentioned in Section 1, initiality accents are analyzed as left-aligned $\varphi$-heads throughout the current article. We return to this issue in Section 5.2 .

\subsection{The syntax-prosody interface}

It will be tacitly, and sometimes explicitly, assumed throughout this article that the syntaxprosody correspondence is governed by a set of competing Optimality Theoretic constraints (OT, Prince \& Smolensky 1993). These constraints govern the relation between prosodic and syntactic edges, while simultaneously taking into account factors of information structure, prosodic well-formedness, and phrase length. This view on the syntax-prosody interface is based on a long line of previous publications (among many others Selkirk 1996; 2011; Truckenbrodt 1999; Féry \& Samek-Lodovici 2006; Elordieta 2007; 2015; Itô \& Mester 2007; 2012; 2019a; 2019b; Feldhausen 2010; 2016; Féry 2013; Myrberg 2013b; Ishihara 2014; 2015; Elfner 2015; Bennett, Elfner \& McCloskey 2016; 2019; Kalivoda 2018). Laying out the full workings of the interactions between OT-constraints that generate the prosodic structures described here lies beyond the scope of this article and will be left for future research (but cf., Myrberg 2019). Nonetheless, this section reviews the most important constraints that are assumed to be responsible for the prosodic structures observed in Section 4.

An important aspect of the syntax-prosody interface is that there can be optionality in the syntax-prosody correspondence. This means that one and the same syntactic structure can result in several different prosodic output structures (cf., Myrberg 2013b). Factors that govern the variation in the syntax-prosody correspondence include information structure and phrase length, as well as speech style and individual variation.

The constraints that govern the relation between syntactic and prosodic edges are assumed here to be the Match constraints developed by Selkirk (2011), (3).

Match theory of syntactic-prosodic constituency correspondence.

a. MatchClause

A clause in syntactic constituent structure must be matched by a corresponding prosodic constituent, call it $\mathrm{t}$, in phonological representation.

b. MatchPhrase

A phrase in syntactic constituent structure must be matched by a corresponding prosodic constituent, call it $\varphi$, in phonological representation.

c. MatchWord

A word in syntactic constituent structure must be matched by a corresponding prosodic constituent, call it $\omega$, in phonological representation.

An important assumption behind these constraints is that the syntax-prosody interface is separately governed on three different levels. The morphosyntactic word has a correspondence with the $\omega$, the syntactic phrase has a correspondence with the $\varphi$, and the syntactic clause has a correspondence with the $\mathrm{t}$. How the syntactic word, phrase, and clause should be formally defined in terms of nodes in the generative model of syntax is yet to be fully understood. For
Figure 3 Initiality accent on compound. Adapted from Myrberg (2010: 56). 
the purposes of the current paper, it will suffice to assume that any XP is matched to $\varphi$-edges (see also e.g., Truckenbrodt 1999), and any CP is matched to t-edges (especially the CP to เ correlation is, however, a simplification, cf., e.g., Selkirk 2011; Myrberg 2013b; Hamlaoui \& Szendrői 2017).

The Match constraints interact with a constraint STRESSFOCUS, formulated as in (4) from Truckenbrodt (1995: 160, though Truckenbrodt refers to this constraint as FocUs).

STRESSFOCUS: If $\mathrm{F}$ is a focus and DF is its domain, then the highest prominence in DF will be within F. (Truckenbrodt 1995: 160)

In addition, the Match constraints interact with constraints that govern the relation between phonological constituents and their heads. HEADEDNESS (5) is inviolable, which means that every phonological constituent in the output structure will have one head (Selkirk 1996).

HEADEDNESS: Any $C^{\mathrm{i}}$ must dominate a $\mathrm{C}^{\mathrm{i}-1}$ (except if $\mathrm{C}^{\mathrm{i}}=\sigma$ ).

e.g., A PWd must dominate a Ft. (Selkirk 1996)

ALIGNHEAD (6)-(7) is a family of constraints that govern the location of heads inside prosodic constituents. The formulations of ALIGNHEAD in (6)-(7) are from Féry \& Samek-Lodovici (2006), though they refer to it as HP and HI, respectively (see also McCarthy \& Prince 1993; Féry 2013). AligNHEAD as formulated in (6)-(7) will place a phonological head at the right constituent edge. In addition, a constraint that aligns $\varphi$-heads with their left edges must be active in Stockholm Swedish, to account for the initiality accent.

$$
\text { AlignHEAD, t: Align the right boundary of every ı with its head(s). }
$$

AlignHEAD, $\varphi$ : Align the right boundary of every $\varphi$ with its head(s).

STRESSFOCUS is higher ranked than AlignHEAD, which means that under e.g., narrow focus, the head appears at the right edge of the focused constituent rather than at the right edge of the phonological constituent (Myrberg 2010).

In addition to the above mentioned constraints, some constraints which control phrase length must be assumed to affect the prosodic phrasing. These account for the phrasing differences between long and short constituents. Constraints that may play a role in this are binarity constraints (e.g., Itô \& Mester 2007; 2019b).

\section{Experimental design}

Five native Stockholm Swedish speakers read question-answer pairs presented to them on a laptop screen. Their speech was recorded with the built-in speakers of an Edirol R-04 device.

The target sentences consisted of a sentence-initial subject, followed by a finite verb phrase. Subject length was varied, so that subjects consisted of either two $\omega$ 's (8a), three $\omega$ 's (9a), four $\omega$ 's (10a), or five $\omega$ 's (11a) (for discussion and definition of the $\omega$ in Swedish see Riad 2014; Myrberg \& Riad 2015). Each target sentence was preceded by a question designed to trigger information-structural focus either inside the verb phrase (8b)-(11b), or inside the subject (8c)-(11c). ${ }^{9}$ The context questions rendered the non-focused parts of the sentences informationstructurally given.

Subject length: $2 \omega$

a. [ Den bruna haren $]_{\mathrm{S}}[\text { bor i parken. }]_{\mathrm{VP}}$ the brown hare lives in park.the

'The brown hare lives in the park.'
b. Var bor den bruna haren?
where lives the brown hare
'Where does the brown hare live?'
(triggers VP-focus) 
c. Vilket brunt djur bor i parken? which brown animal lives in park.the

(9)

Subject length: $3 \omega$

a. [ Den bruna haren med ungar $]_{S}[\text { bor i parken. }]_{V P}$ the brown hare with kids lives in park.the

'The brown hare with kids lives in the park.'

b. Var bor den bruna haren med ungar? (triggers VP-focus) where lives the brown hare with kids 'Where does the brown hare with kids live?'

c. Vilken brun hare bor i parken? (triggers subject-focus) which brown hare lives in park.the 'Which brown hare lives in the park?'

\section{(10) Subject length: $4 \omega$}

a. [ Den bruna haren med många ungar $]_{\mathrm{S}}[\text { bor i parken. }]_{\mathrm{VP}}$ the brown hare with many kids lives in park.the 'The brown hare with many kids lives in the park.'

b. Var bor den bruna haren med många ungar? (triggers VP-focus) where lives the brown hare with many kids 'Where does the brown hare with many kids live?'

c. Vilken brun hare bor i parken? (triggers subject-focus) which brown hare lives in park.the 'Which brown hare lives in the park?'

Subject length: $5 \omega$

a. [ Den bruna haren med många söta ungar $]_{\mathrm{S}}[\text { bor } \mathrm{i} \text { parken. }]_{\mathrm{VP}}$ the brown hare with many cute kids lives in park.the 'The brown hare with many cute kids lives in the park'

b. Var bor den bruna haren med många söta ungar? (triggers VP-focus) where lives the brown hare with many cute kids 'Where does the brown hare live?'

c. Vilken brun hare bor i parken? which brown hare lives in park.the (triggers subject-focus) 'Which brown hare lives in the park?'

There were ten sets of items as in (8)-(11). Five sets had tone accent 1 words in the subject, and the other five had tone accent 2 words in the subject. ${ }^{10}$ Each question-answer pair was repeated three times. In total, this resulted in a corpus of 1200 read sentences (10 items *4 length conditions * 2 focus structures * 3 repetitions * 5 speakers $=1200$ sentences $)$. The full set of target sentences and questions is provided in Appendix A.

\subsection{Annotation procedure}

The sentences were annotated using Praat (Boersma \& Weenink 2016). The left and right edges of each word in the subject were manually inserted. Thereafter, a script was used to automatically insert three tonal target points (points A, B, C in Figures 4 and 5) in the initial and the final $\omega$ of the subject. After the tonal points had been automatically inserted, the author controlled all inserted points, manually correcting erroneous measurements due to e.g., creaky voice or consonantal effects in the fo contour. A detailed account of the procedure

10 In the tone accent 1 condition, the nouns have tone accent 1 , whereas the adjectives have tone accent 2 . This is because the adjective definite marker is specified for tone accent 2 , which makes it impossible to find enough bisyllabic adjectives with tone accent 1 in sentences with the relevant structure. 


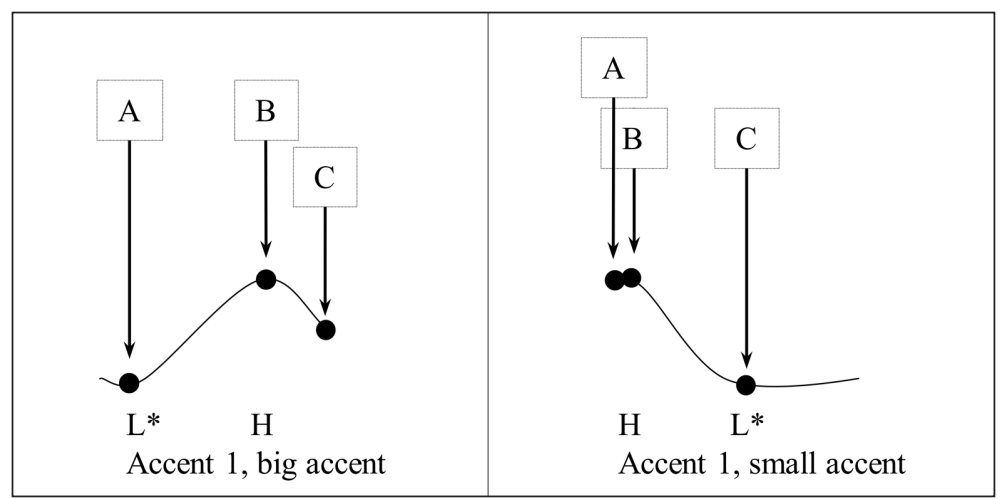

\begin{tabular}{|l|l|l|l|}
\hline $\mathrm{A}$ \\
\hline
\end{tabular}

through which each point was defined is provided in Sections 3.1.1 (tone accent 1) and 3.1.2 (tone accent 2). ${ }^{11}$

Crucially, the annotation procedure resulting in tonal target points did not rely on any subjective judgment or analysis regarding which tonal contour the target word carried, but operated independently of the author's (or any other speaker's) judgement regarding the phonological representation of the contour. This means that the script was designed so as to apply independently of any assumption about whether the target word was assigned a small accent contour (tone accent $1: \mathrm{HL}^{*}$, tone accent $2: \mathrm{H}^{*} \mathrm{~L}$, cf., Table 1), or a big accent contour (tone accent 1: $\mathrm{L}^{*} \mathrm{H}$, tone accent 2: $\mathrm{H}^{*} \mathrm{LH}$, cf., Table 1). One necessary consequence of this is that the final annotation contains points that do not correspond to phonological $\mathrm{H}$ or L targets (specifically, point $\mathrm{C}$ in the tone accent 1 big accent, point $\mathrm{A}$ in the tone accent 1 small accent, and point $\mathrm{C}$ in the tone accent 2 small accent, cf., Figures 4 and 5).

The second step of the annotation procedure took place after the completion of the semiautomatic annotation, and consisted in the author making an auditory and visual judgment of whether there was a big accent or a small accent contour in each word in the subject. This procedure is described in Section 3.1.3.

\subsubsection{Tone accent 1 annotation procedure}

For the tone accent 1 words, the highest point in the word was first selected (point B). After that, the lowest point between point B and the left edge of the word was selected (point A). Finally, the lowest point between point B and the right edge of the word was selected (point C). Figure 4 shows how this automatic annotation procedure resulted in annotations for words with big accents (left panel) and small accents (right panel).

The result of this annotation procedure is that for words with tone accent 1 big accent contours, points A and B correspond to tonal targets ( $\mathrm{L}^{*}$ and $\mathrm{H}$ respectively). Point $\mathrm{C}$ does not correspond to a tonal target in words with big accents. Instead, it appears at the right edge of the word (commonly toward the end of a tonal fall toward a L\%, or in the middle of a plateau binding together the big accent $\mathrm{L}^{*} \mathrm{H}$ contour with a following $\mathrm{HL}^{*}$ contour).
Figure 4 Result of the annotation procedure for tone accent 1 words with big accents (left panel) and small accents (right panel). See text for explanation.

Figure 5 Result of the annotation procedure for tone accent 2 words with big accents (left and middle panels) and small accents (right panel). See text for explanation. 
For words with small accents, points $B$ and $C$ correspond to tonal target points $\left(\mathrm{H}\right.$ and $\mathrm{L}^{*}$ respectively). Point A does not correspond to a tonal target, but appears at a minimal distance from point B. ${ }^{12}$

\subsubsection{Tone accent 2 annotation procedure}

The tone accent 2 procedure was necessarily slightly more complex than the corresponding one for tone accent 1 words, due to the two-peak shape of the tone accent 2 big accents. Figure 5 illustrates the result of the annotation procedure for tone accent 2 words. The left and middle panels show big accents. In the left panel, the right peak is higher, and in the middle panel the left peak is higher. It should be noted that these types are assumed to have the same tonal representation. They are illustrated separately because the annotation proceeded in different ways for these types. The right panel shows a small accent.

For all accent 2 words, the f0 maximum in the word was identified first (point $\mathrm{C}$ in the left panel of Figure 5 and point A in the middle and right panels). Next, information about the location of the fo maximum in relation to the word edges was extracted.

If the f0 maximum in the word occurred in the right half of the target word (the left panel of Figure 5), this point was named point $\mathrm{C}$. It represents the right $\mathrm{H}$ in a big accent $\mathrm{H}^{*} \mathrm{LH}$ contour. Point A was subsequently inserted at the fo maximum between the left word edge and a point 0.6 seconds to the left of point $C .{ }^{13}$ Finally, point B was inserted at the fo minimum between points A and C. ${ }^{14}$

If the f0 maximum of the entire word occurred in the left half of the word (the middle and right panels of Figure 5) this point was named point A. This point represents either the $\mathrm{H}^{*}$ of a big accent $\mathrm{H}^{*} \mathrm{LH}$ contour (middle panel) or the $\mathrm{H}^{*}$ of a small accent $\mathrm{H}^{*} \mathrm{~L}$ contour (right panel). Point $\mathrm{B}$ was inserted at the f0 minimum between point $\mathrm{A}$ and the right edge of the word. Last, point $\mathrm{C}$ was inserted at the $\mathrm{f0}$ maximum between point $\mathrm{B}$ and the right word edge. Point $\mathrm{C}$ in these cases may represent the right high in a big accent $\mathrm{H}^{*} \mathrm{LH}$ (middle panel). Alternatively, if the word has a small accent, point $\mathrm{C}$ does not represent any tonal target and has a $\mathrm{Hz}$ value very close to point B (right panel).

\subsection{Validity of binary judgments}

The author judged each word in the subject with respect to whether the word carried a big or a small accent. This was a binary judgment, looking only at the tonal contour, i.e., if there was a rise or a fall associated with the stressed syllable in accent 1 words ( $\mathrm{L}^{*} \mathrm{H}$ or $\mathrm{HL}^{*}$ ), and whether there was one or two peaks in accent 2 words $\left(\mathrm{H}^{*} \mathrm{~L}\right.$ or $\left.\mathrm{H}^{*} \mathrm{LH}\right)$. A question mark was used to indicate any case where it was difficult to decide between the two options. In general, the binary choice between big and small accent was uncomplicated to make. This is reflected in the small number of question marks used in the annotation. In total, 4192 words were labelled. ${ }^{15}$ Of these, 1886 were labelled big accent, 2276 small accent, and 30 had a '?' after their label. Words marked with '?' are excluded in the analyses below.

12 The representation $\mathrm{HL}^{*}$ for the word accent fall in tone accent 1 implies that the $\mathrm{L}^{*}$ tone is associated with the stressed syllable, whereas the $\mathrm{H}$ tone precedes the stressed syllable. Whenever the initial syllable of the word is stressed, as is the case for the target words in this experiment, the highest point in the HL* sequence may thus appear outside the left edge of the word (e.g., Bruce 1977; 1998). The annotation procedure reported in Figure 1 does not take this into account. However, this is of no consequence to the account in this article, as the size of small accents will not be relevant.

13 The value 0.6 seconds was an estimation intended to prevent the point B from being placed on the second peak in the word (too close to point A). On a few occasions, 0.6 seconds was too short, so that the tonal target point was placed in the rise toward the second high point in the $\mathrm{H}^{*} \mathrm{LH}$ contour, instead of in the first $\mathrm{H}$. Manual corrections were made in these cases.

14 In initiality accents, the right H-tone frequently floats away far to the right (Roll, Horne \& Lindgren 2009; Myrberg 2010). This sometimes causes the $\mathrm{H}$ to appear outside the right edge of the word. Whenever the rise toward the (right) $\mathrm{H}$ in a $\mathrm{H}^{*} \mathrm{LH}$ or $\mathrm{L}^{*} \mathrm{H}$ contour continued outside the word boundary, the point representing this $\mathrm{H}$ was manually moved to the fo maximum of the peak.

15 Four different length conditions with 2, 3, 4, and $5 \omega$ 's respectively. Each length condition was read 300 times: 5 items $\times 3$ repetitions $\times 2$ tone accents $\times 2$ focus conditions $\times 5$ speakers. $(300 \times 2)+(300 \times 3)+$ $(300 \times 4)+(300 \times 5)=4200$. Two words were annotated in each sentence. Two sentences from two different speakers were lost due to technical problems, which caused a loss of 8 words. Thus, 4912 words were labelled. 
In order to verify the validity of the subjective judgments, they were compared with the results of the f0 measure from the tonal annotation. Recall that the annotation procedure that extracted the tonal targets operated independently of the binary judgment. Figure 6 shows the f0 measure in words judged to have big accent versus words judged to have small accent. The left panel shows the $\mathrm{f} 0$ of annotation point $\mathrm{B}$ in accent 1 words. The right panel shows the f0 measure of annotation point $\mathrm{C}$ in accent 2 words. Point $\mathrm{B}$ for accent 1 and point $\mathrm{C}$ for accent 2 are the points where the crucial difference between big and small accent is expected given the tonal representation of big versus small accents (cf., Figures 4 and 5). In Figure 6, data from all five speakers and from the initial as well as the final words of the subject is plotted together. In spite of this, there is a clearly significant difference between the fo among words labelled big accent and words labelled small accent. This difference is present for words with tone accent 1 as well as tone accent 2 .

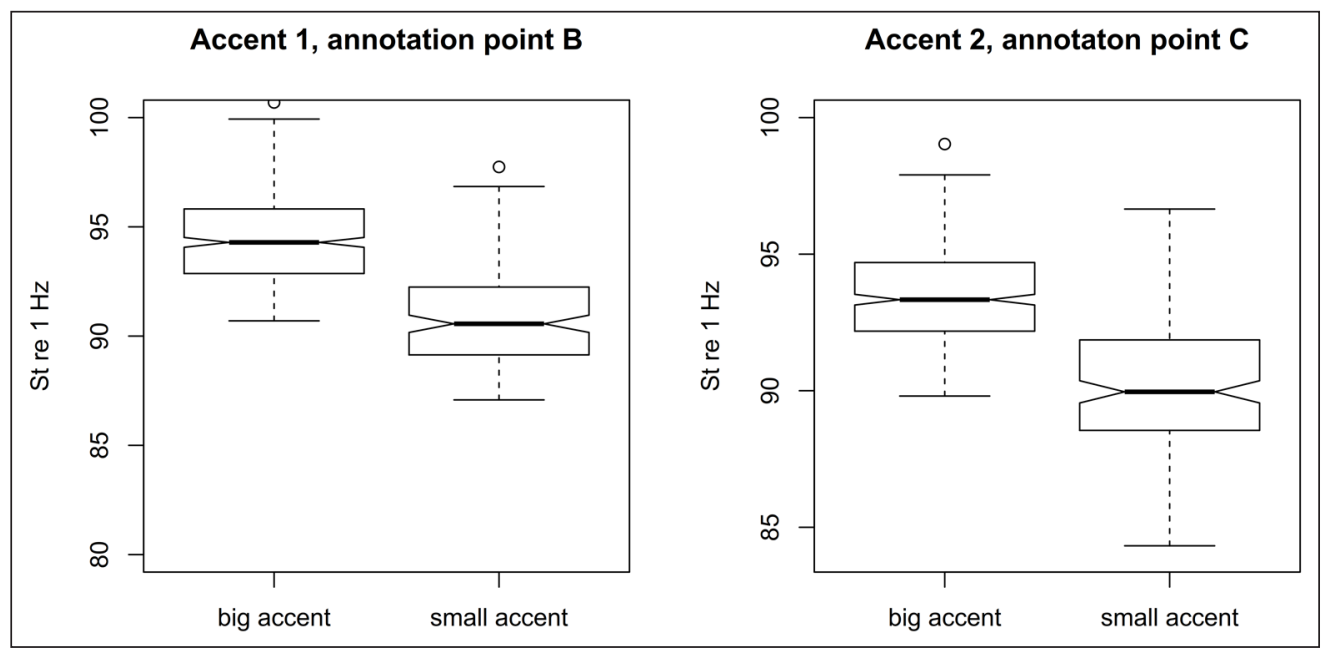

Importantly, no judgment was made with respect to perceived degree of prominence. Though the shape of the f0 contour is strongly related to the perceived degree of prominence, other factors including scaling and duration also play a role for the perceived degree of prominence. Perceived degree of prominence is a gradient phenomenon, which cannot be adequately described on a binary scale, and possibly cannot be adequately annotated by a single speaker, cf., e.g., Strangert \& Heldner (1995a; 1995b). See Heldner (2001) and Hansson (2003) for discussion and studies regarding perceived degree of prominence in Swedish. Thus, judging the degree of prominence of a word is more complex than judging the tonal contour on that word, at least for Swedish, where the number of possible tonal contours on any given word is small.

\section{Results}

This section describes the big accents in the preverbal subjects. Sections 4.1-4.4 describe the distributional patterns of big accents. Section 4.1 discusses subjects that contain a single big accent. Section 4.2 discusses subjects that contain two big accents. Section 4.3 discusses subjects that contain three big accents. Each section provides the phonological bracketing of the subjects, fo contours which illustrate these structures, and a table illustrating the frequency of the structures in question. Details on the individual variation among the speakers can be found in Appendix B. Section 4.4 compares big accents that express narrow focus, i.e., nuclear big accents, to big accents that do not express focus, i.e., prenuclear big accents.

\subsection{Subjects with one big accent, one $\varphi$}

A central observation is that the subject always contains at least one big accent, cf., the ungrammaticality of (12c). ${ }^{16}$ Note that the big accent is obligatory even when the subject is information-structurally given. Under the assumption that every big accent is head of one $\varphi$ (cf., Sections 1 and 5.1), the preverbal constituent obligatorily forms a $\varphi$, as indicated with round brackets in (12a) (Figure 7) and (12b) (Figure 8).
Figure 6 F0 measures of words rated as big versus small accents. The left panel shows the fo measure of annotation point $B$ (see Figure 4 for explanation), in words with accent 1 , which are rated as big accent and small accent, respectively. The right panel shows the fo measure of annotation point C (see Figure 5 for explanation), in words with accent 2 , which are rated as big accent and small accent, respectively. 

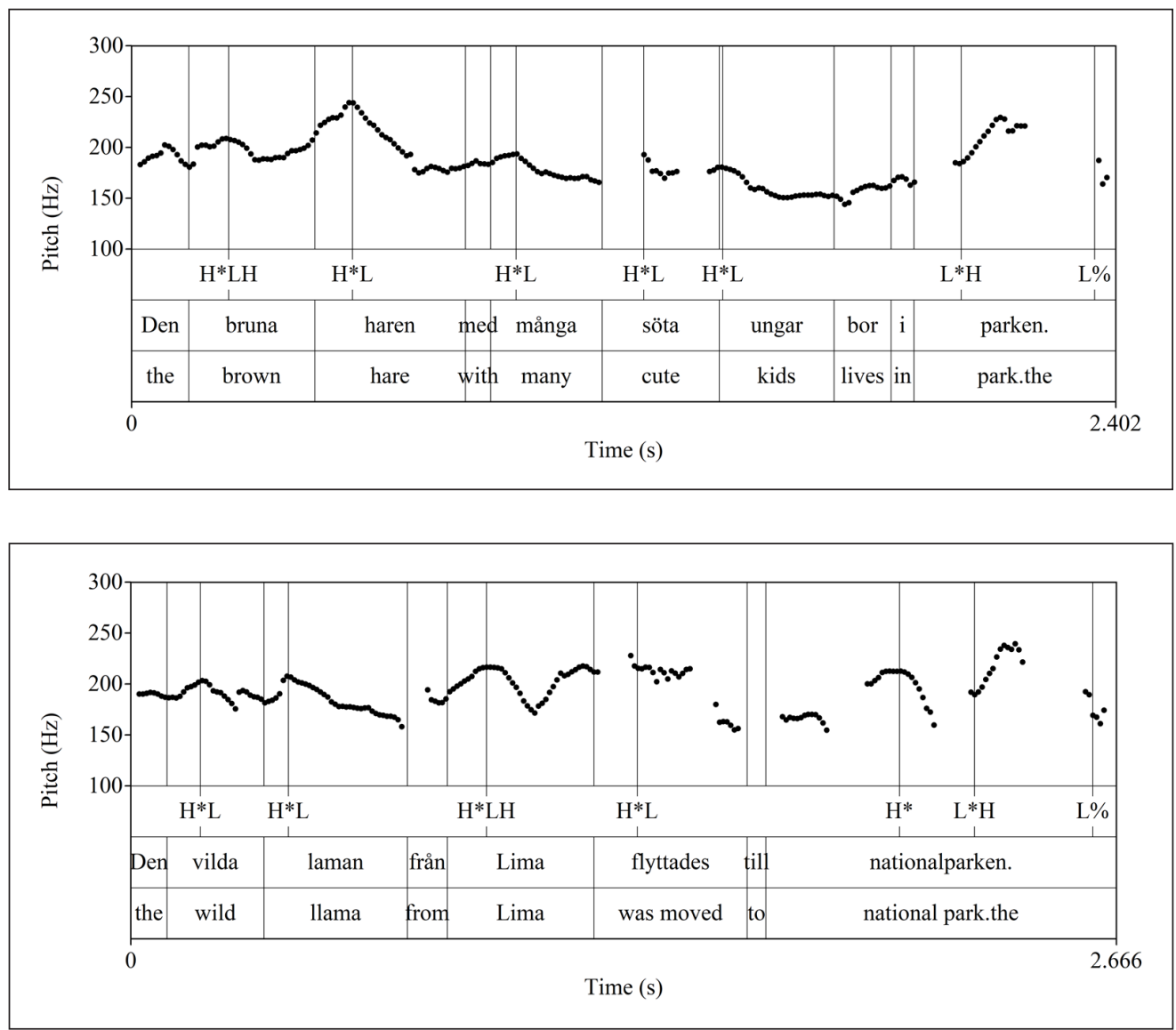

(12)

Locations of big accents inside preverbal subjects with one big accent. Round brackets represent $\varphi$-edges. Curly brackets represent t-edges. See (11) for gloss and translation.
a. Den bruna haren med många söta ungar bor [i PARKEN. $]_{\text {Focus }}$ $\{(\quad$ BIG left
)( BIG $\left.\left.^{\text {nuc }}\right)\right\}$
b. Den bruna haren med många söta ungar bor [i PARKEN. $]_{\text {Focus }}$ $\left\{\left(\quad \mathrm{BIG}^{\text {right }}\right)(\mathrm{BIG})\right\}$
c. Den bruna haren med många söta ungar bor [i PARKEN. ] $]_{\text {Focus }}$ $*\left\{\left(\quad \mathrm{BIG}^{\mathrm{nuc}}\right)\right\}$
d. Den bruna haren med många söta ungar bor $[\text { i PARKEN. }]_{\text {Focus }}$
$*\{($
BIG

One of the most interesting aspects of the obligatory big accent regards its position within the preverbal subject. As seen from the contrast between (12a) and (12b), the big accent may appear either on the leftmost or on the rightmost $\omega$ of the subject. However, it may not appear on a subject-medial $\omega$, cf., the ungrammaticality of (12d). Assuming that every big accent is head of one $\varphi$, we can refer to (12a) as left-headed, and (12b) as right-headed. The big accent that appears in the left-headed $\varphi$ is an initiality accent (cf., Sections 2.3 and 5.2, see also Myrberg 2010; 2013b; Myrberg \& Riad 2015).

In total, 557 of the 1200 recorded subjects have a single big accent $(46,4 \%)$. Figure 9 shows the frequency of subjects that contain a single big accent for subjects of different lengths.

We see in Figure 9 that short subjects have a single accent more frequently than long subjects (cf., Sections 4.2 and 4.3). Short subjects are almost always phrased as a single $\varphi$.

We also see in Figure 9 that the location of focus is an important factor for whether a subject is left-headed (12a) or right-headed (12b). When containing only one big accent, given subjects tend to have an initiality accent (left-headed, (12a)), whereas focused subjects in principle obligatorily have right-aligned prenuclear accents (right-headed, (12b)). This is entirely expected given what we know about the interface between prosody and information structure in Germanic languages. It is well observed that languages like English, German and Swedish have a strong requirement that the rightmost word in a focused constituent carry a so-called
Figure 7 The f0 contour for (12a). 'The brown hare with many cute kids lives in the park'.

Figure 8 The f0 contour for (12b). 'The wild llama from Lima was moved to the national park'. Note that the f0 contour here is illustrated with a different experiment sentence than in (12). All prosodic options cannot be illustrated with the same sentence throughout the article. However, no significant differences could be found between the different items in terms of prosodic structure. 


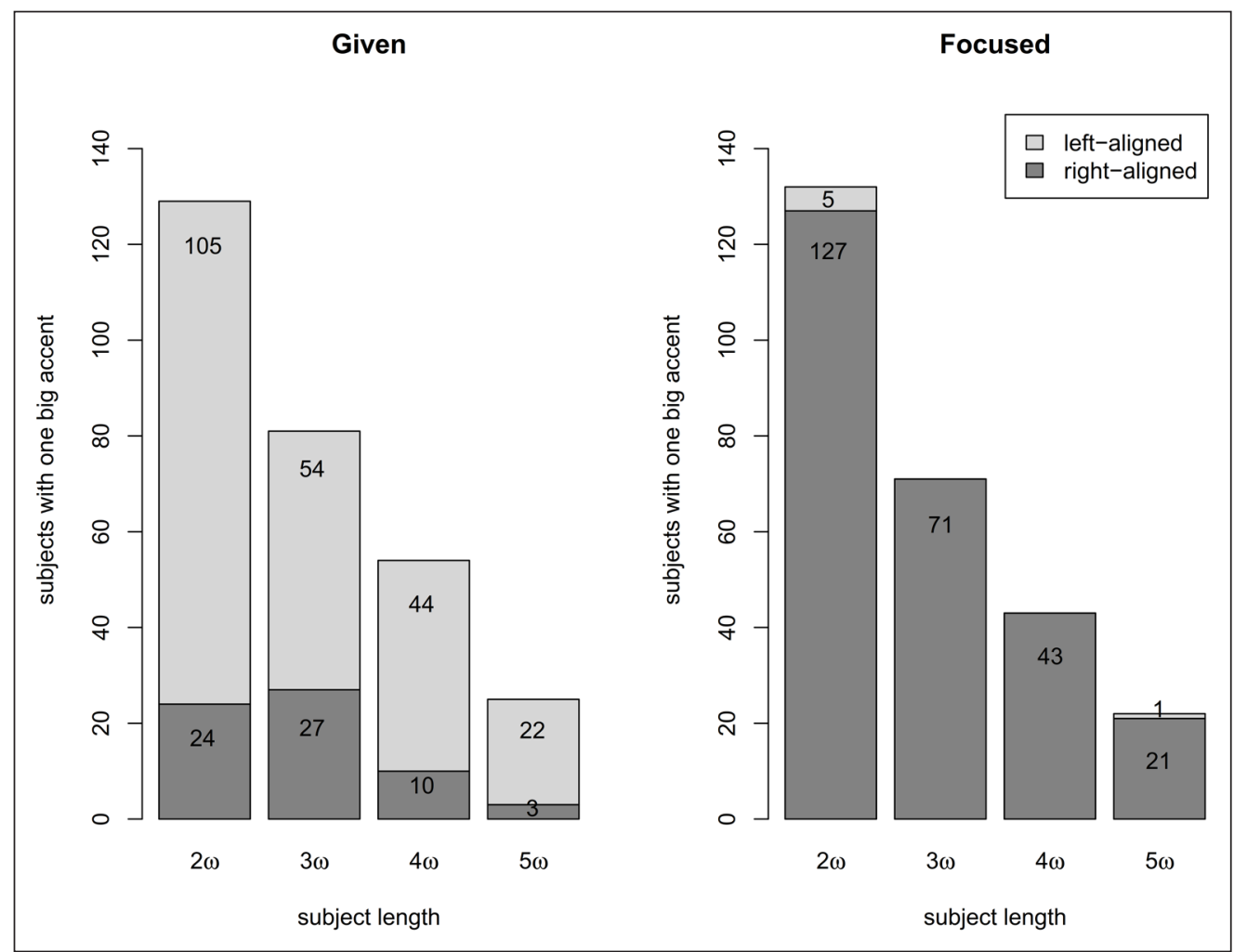

nuclear accent, i.e., the strongest prominence in the intonation phrase (among others Bruce 1977; Selkirk 1984; Féry 1993; Selkirk 1995; Féry \& Samek-Lodovici 2006; Myrberg 2010; Féry 2013). The left-aligned head in (12a) fails to satisfy this requirement, and thus cannot express narrow focus on the subject. We may note that the left-aligned head is the most common realisation of given subjects with a single big accent, but that right-aligned subjects are also an available option. ${ }^{17}$

\subsection{Subjects with two big accents, two $\varphi$ 's}

We have seen that the subject obligatorily contains at least one big accent, which is the head of a $\varphi$. It is, however, also common for the subject to contain two big accents. Under the assumption that each big accent is the head of one $\varphi$, subjects with two big accents are divided into two $\varphi$ 's. In terms of left- versus right-headedness of the two $\varphi$ 's, there are three available options, shown in (13). In (13a) and Figure 10, both $\varphi$ 's are right-headed. In (13b) and Figure 11, the first $\varphi$ is left-headed whereas the second is right-headed. In (13c) and Figure 12, both $\varphi$ 's are leftheaded. The logically possible option in (13d), where the first $\varphi$ is right-headed and the second is left-headed, is unattested.

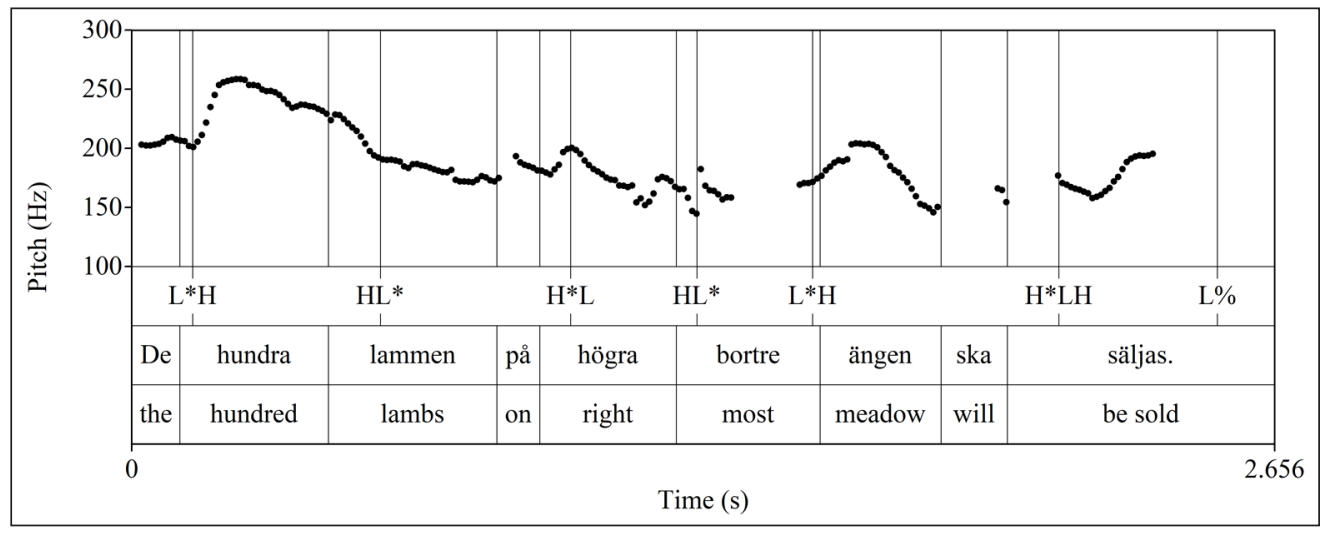

17 In the data there are six left-headed focused subjects. These are presented here and seen in the bar plot as a small area of light grey in 2 and $5 \omega$ focused subjects. However, native language intuition of the author says that these readings are in fact not grammatical, and this intuition is supported by the well described fact that focused constituents have a strong rightmost prominence in Swedish and in other Germanic languages (e.g., Selkirk 1984; Féry 1993; 2013; Bruce 1977). It is therefore assumed that in these cases, the speakers have failed to adapt their reading to the context. Nonetheless, all results are reported here for the sake of objectivity.
Figure 9 Number of given and focused subjects phrased in a single $\varphi$, in each length condition. Short subjects contain a single big accent more often than long subjects and therefore have higher bars. The total for each bar is 150. Given subjects are shown to the left and focused subjects to the right. Light bars indicate left-headed subjects (12a) and dark bars indicate right-headed subjects (12b).

Figure 10 F0 contour of (13a). 'The one hundred lambs on the rightmost meadow which is farthest away will be sold.' 

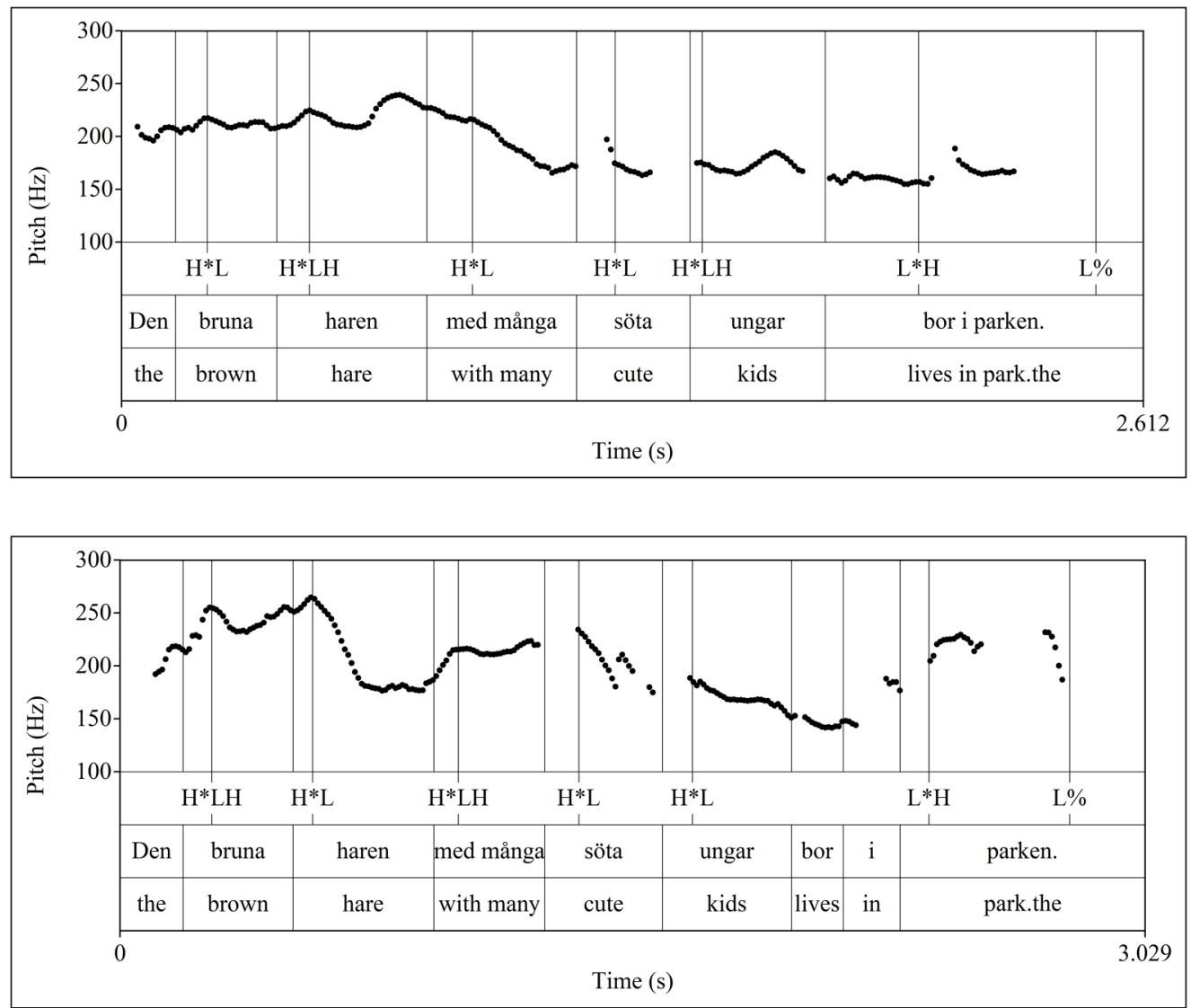

(13)

Locations of big accents inside preverbal subjects with two big accents. Round brackets represent $\varphi$-edges. Curly brackets represent t-edges. See (11) for gloss and translation. $\left\{\left(\quad B I G^{\text {right }}\right)(\right.$
BIG $\left.{ }^{\text {right }}\right)($
$\left.\left.\mathrm{BIG}^{\text {nuc }}\right)\right\}$
a. Den bruna haren med många söta ungar bor [ $i$ PARKEN. $]_{\text {Focus }}$
b. Den bruna haren med många söta ungar bor $[\text { i PARKEN. }]_{\text {Focus }}$

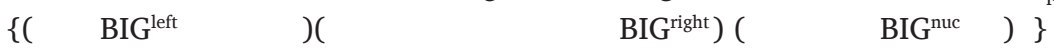
c. Den bruna haren med många söta ungar bor $[\mathrm{i} \text { PARKEN. }]_{\text {Focus }}$

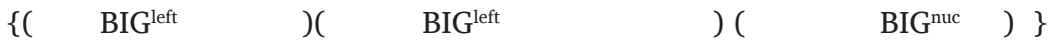
d. *Den bruna haren med många söta ungar bor [ i PARKEN. $]_{\text {Focus }}$ $\left\{\left(\mathrm{BIG}{ }^{\text {right }}\right)\left(\right.\right.$ BIG $\left.^{\text {left }}\right)\left(\right.$ BIG $\left.\left.^{\text {nuc }}\right)\right\}$

Figure 13 shows the number of subjects with two big accents for different subject lengths. The three shades of grey inside each bar indicate the three structures in (13a)-(13c). ${ }^{18}$

\subsection{Subjects with three big accents, three $\varphi$ 's}

In a comparatively small number of subjects, the subject contains three big accents and is thus divided into three $\varphi$ 's. Specifically, this is the case in $9 \%$ of subjects with $4 \omega$, and $16 \%$ of subjects with $5 \omega$. The patterns with three big accents are shown in (14). ${ }^{19}$ Contours for each pattern are provided in Figures 14 and 15. Figure 16 shows the frequency of each pattern.
Figure $11 \mathrm{~F} 0$ contour of (13b). 'The brown hare with many cute kids lives in the park.'

Figure 12 F0 contour of (13c) 'The brown hare with many cute kids lives in the park.'

18 Note that the pattern in (13c) is (almost) unattested for focused subjects. This is because this pattern lacks a big accent on the final word of the subject. It is predicted that this pattern should not occur at all, since the final word of a focused constituent is normally required to have a big accent in all Germanic languages, cf., Footnote 17.

19 In (14a), the word söta is included in the same $\varphi$ as många, creating a sequence of two rhythmically similar $\varphi$ 's in the first part of the t. An alternative analysis would be that söta belongs to the same $\varphi$ as ungar, and at this point, there is no way of determining empirically which of these analyses is preferable. A better understanding of left-headed $\varphi$ 's which are not t-initial (as in 12c) may be of interest here, to see if there are in fact rhythmic requirements on such $\varphi$ 's. See Footnote 20 for an alternative analysis of the postfocal area. 

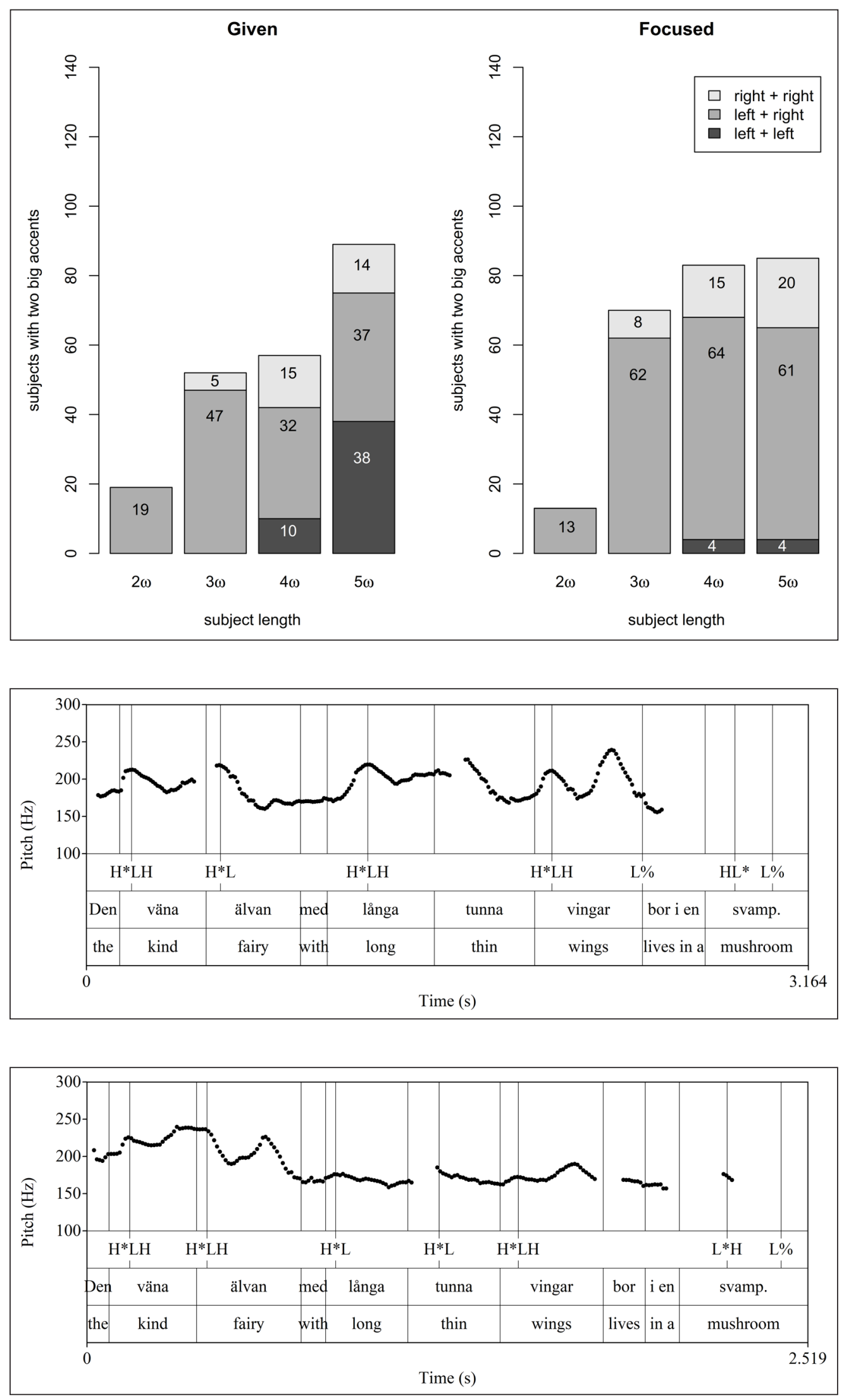

(14) Locations of big accents inside preverbal subjects with three big accents. Round brackets represent $\varphi$-edges. Curly brackets represent t-edges. See (11) for gloss and translation.

a. Den bruna haren [ med många söta UNGAR $]_{\text {Focus }}$ bor i parken. $\left\{\left\{\left(\mathrm{BIG}^{\text {left }}\right)\left(\mathrm{BIG}^{\text {left }}\right)\left(\mathrm{BIG}^{\text {nuc }}\right)\right\} \quad\right\}$

b. Den bruna haren med många söta ungar [ bor i PARKEN. ] $]_{\text {Focus }}$ $\left\{\left(\mathrm{BIG}^{\text {left }}\right)\left(\mathrm{BIG}^{\text {right }}\right)\left(\mathrm{BIG}^{\text {right }}\right)\left(\mathrm{BIG}^{\text {nuc }}\right)\right\}$
Figure 13 Number of given and focused subjects phrased in two $\varphi$ 's, in each length condition. The light part of each bar represents subjects with two right-aligned big accents (13a). The mid-grey represents subjects with one initiality accent and one leftaligned big accent followed by one right-aligned big accent (13b). The dark part of each bar represents two leftaligned big accents (13c). The total for each bar is 150 .

Figure 14 F0 contour of (14a). 'The kind fairy with long thin wings lives in a mushroom?. Note that the subject is focused in this structure, because this structure is considerably more common among focused subjects than given subjects.

Figure 15 F0 contour of (14b). 'The kind fairy with long thin wings lives in a mushroom'. 


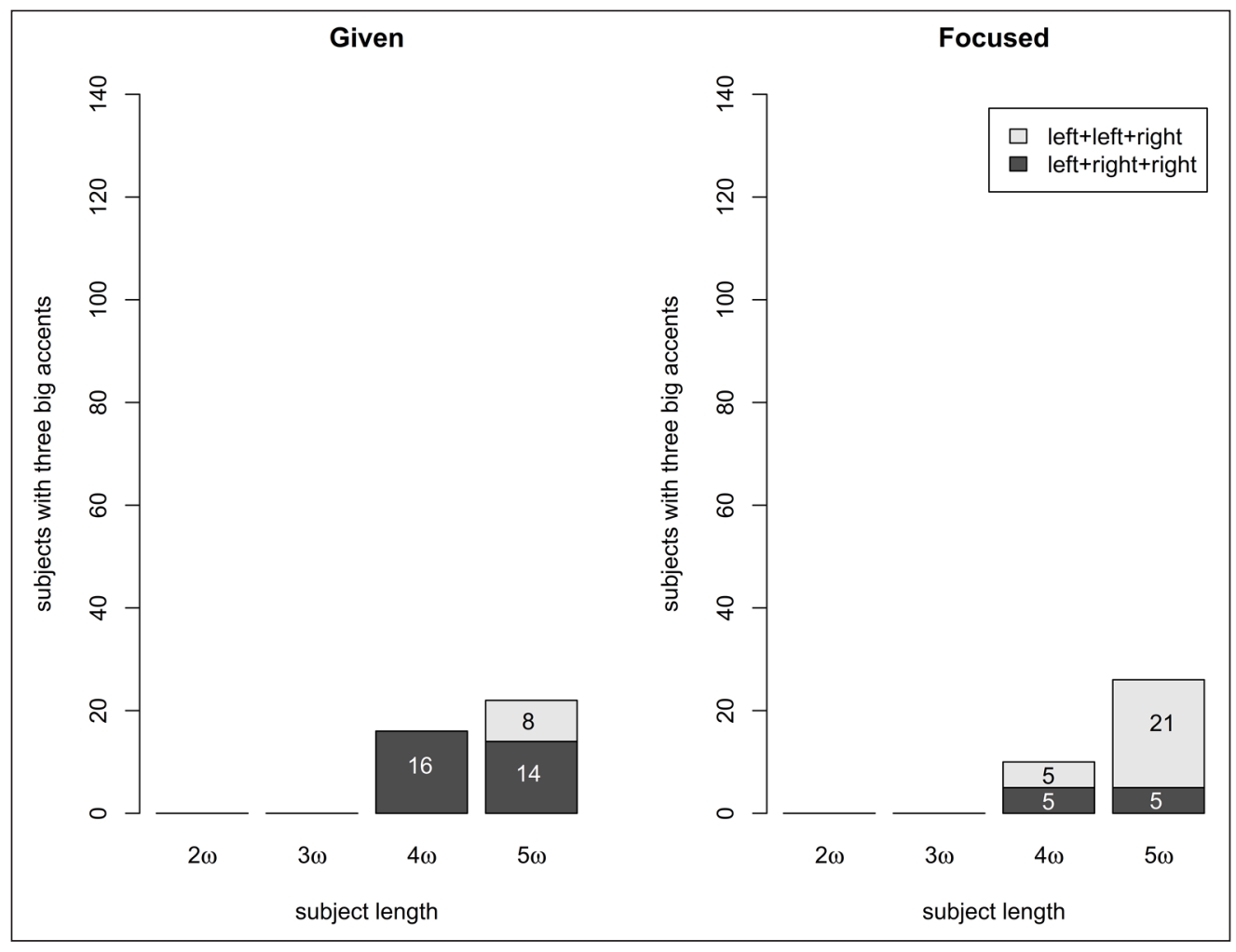

4.4 Scaling of nuclear versus prenuclear big accents

As discussed in Sections 1, 2.2 and 5.1, this article argues that a distinction should be made between nuclear big accents (t-heads) and prenuclear big accents ( $\varphi$-heads). In relation to this discussion it is interesting to look at the scaling of nuclear versus prenuclear accents. The relevant comparison is between the rightmost word in focused versus given subjects, i.e., the nuclear big accent on information-structurally focused ungar in (15a), and the prenuclear big accent on information-structurally given ungar in (15b). ${ }^{20}$

Comparison between prenuclear big accent and nuclear big accent on the final word of the subject ungar 'kids'. Round brackets represent $\varphi$-edges. Curly brackets represent t-edges. See (11) for gloss and translation.
a
Den bruna haren
$\left\{\left(\quad \mathrm{BIG}^{\text {left }}\right.\right.$
[
[ med många söta$$
)(
$$
Den bruna haren
med många söta ungar
BIGnuc
bor i parken.

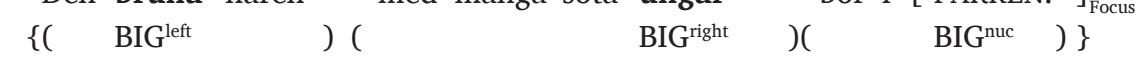

Figures 17 and 18 show the scaling of the right $\mathrm{H}$ in big accents on the rightmost word (ungar in (15)) of information-structurally focused versus information-structurally given subjects. Figure 17 shows tone accent 1 subjects and Figure 18 shows tone accent 2 subjects. It can be observed that big accents have a significantly higher f0 value in the nuclear accents than in the prenuclear accents. This is true for all length conditions in tone accent 1 and tone accent 2 words, except the short accent 2 subjects. Importantly, only subjects which were realized with a big accent are included in the plots. This means that subjects which did not have a big accent on their last word were excluded from the analysis. The difference between nuclear and prenuclear big accents observed here is previously undocumented and to my knowledge previously unstudied for Swedish.

20 In (15a) one could also assume the structure in (i), with an extrametrical post-focal area. The structures in (15a) and (i) are empirically distinct. Whereas (15a) has a plateau following the big accent $\mathrm{H}^{*} \mathrm{LH} / \mathrm{L}^{*} \mathrm{H}$, (i) has a tonal fall. See Myrberg (2010: 99ff) and Myrberg \& Riad (2015) for description of these phonological structures. The functional difference between (15a) and (i) in relation to e.g., information structure is not fully understood, but see Myrberg (2013a).

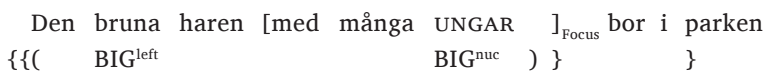

Figure 16 Number of given and focused subjects phrased in three $\varphi$ 's, in each length condition. Only the two longest subject types exhibit three big accents. 
It is worth noting that the nuclear accents plotted in Figures 17 and 18 are induced by information-structural narrow focus. Nuclear accents also appear in all-new sentences, usually on the rightmost $\omega$ (cf., Myrberg 2010 for detailed discussion and exceptions). Myrberg (2013a) showed that nuclear accents in all-new sentences are scaled lower than nuclear accents induced by narrow or contrastive focus. Further research is necessary to understand the scaling of nuclear accents in all-new sentences.
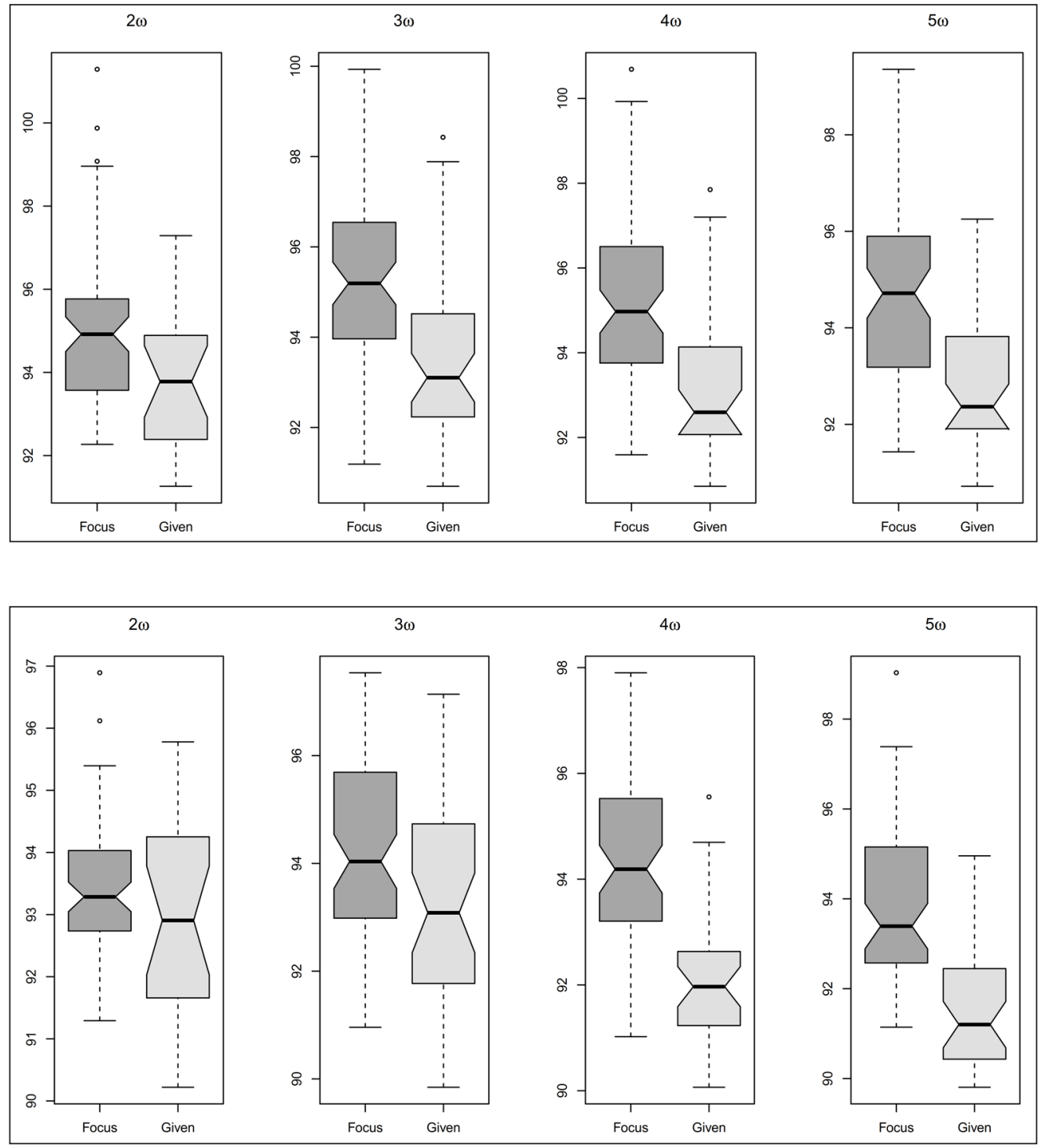

\section{Implications for the prosodic structure}

This section lays out some of the theoretical consequences of the patterns described in Section 4. Specifically, Section 5.1 lays out the arguments for a distinction between the $\mathrm{t}$ and the $\varphi$ in the prosodic hierarchy of Swedish. Section 5.2 lays out the argument of the initiality accent as a left-aligned $\varphi$-head in greater detail. Section 5.2 also shows how this argument accounts for some previously observed distributional facts about the initiality accent. Section 5.3, finally, discusses the $\varphi$-edge that has been assumed to be obligatory after the subjects throughout this article. Some additional evidence for this edge is provided and the argument is extended to other types of preverbal constituents.

\subsection{Arguments for the distinction between $\varphi$ and ।}

The data presented in Section 4 has been claimed to support a distinction between $\varphi$ and เ. The first part of the argument for such a division relates to the sequencing of $\varphi$ 's within the $\mathrm{t}$. Without a domain type governing the $\varphi$, it will not be possible to formulate a rule, which can account for the distribution of right- versus left-headed $\varphi$ 's. Assuming a category $\mathrm{l}$, however, the distribution of left-aligned heads can be stated as follows: If the leftmost $\varphi$ in

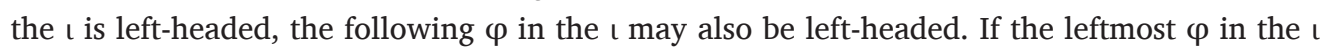

Figure 17 Subjects with tone accent 1 . A comparison of nuclear (15a) versus prenuclear (15b) big accents on the rightmost words of 2 , 3,4 , and $5 w$ subjects. The boxplots show the height, in semitones, of the $\mathrm{H}$ in the big accent 1 contour $L^{*} H$. (Observe that (15) illustrates sentences with tone accent 2 words. See Appendix A for the set of sentences with tone accent 1). Only words labeled big accent in the subjective judgment are plotted. The four panels show subjects of different lengths. Inside each panel, the dark grey box shows the fo for focused subjects (nuclear big accent). The light grey box shows the fo for given subjects (prenuclear accent).

Figure 18 Subjects with tone accent 2. A comparison of nuclear (15a) versus prenuclear (15b) big accents on the final words of 2,3 , 4 , and $5 \omega$ subjects. The boxplots show the height, in semitones, of the right $\mathrm{H}$ in the big accent 2 contour $H^{*} \mathrm{LH}$. Only words labeled big accent in the subjective judgment are plotted. The four panels show subjects of different lengths. Inside each panel, the dark grey box shows the fo for focused subjects (nuclear big accent). The light grey box shows the fo for given subjects (prenuclear big accent). 
is right-headed, the following $\varphi$ in the ı must be right-headed. These distributional patterns of left-headed $\varphi$ 's were illustrated in (12)-(13), and are repeated in (16)-(17).

Locations of big accents inside preverbal subjects with one big accent. Round brackets represent $\varphi$-edges. Curly brackets represent t-edges. See (11) for gloss and translation.
a. Den bruna haren med många söta ungar bor [i PARKEN. $]_{\text {Focus }}$ $\left\{\left(\mathrm{BIG}^{\text {left }}\right)\left(\mathrm{BIG}^{\text {nuc }}\right)\right\}$
b. Den bruna haren med många söta ungar bor [i PARKEN. $]_{\text {Focus }}$ $\left\{\left(\operatorname{BIG}^{\text {right }}\right)\left(B I G^{\text {nuc }}\right)\right\}$
c. Den bruna haren med många söta ungar bor [i PARKEN. $]_{\text {Focus }}$ $*\left\{\left(\quad \mathrm{BIG}^{\text {nuc }}\right)\right\}$
d. Den bruna haren med många söta ungar bor [i PARKEN. $]_{\text {Focus }}$ $*\left\{(\right.$ BIG $\left.)\left(B^{\text {nuc }}\right)\right\}$

(17) Locations of big accents inside preverbal subjects with two big accents. Round brackets represent $\varphi$-edges. Curly brackets represent t-edges. See (11) for gloss and translation.
a. Den bruna haren med många söta ungar bor [i PARKEN. $]_{\text {Focus }}$
$\left\{\left(\mathrm{BIG}^{\text {right }}\right)\left(\mathrm{BIG}^{\text {right }}\right)\left(\mathrm{BIG}{ }^{\text {nuc }}\right)\right\}$
b. Den bruna haren med många söta ungar bor [i PARKEN. $]_{\text {Focus }}$

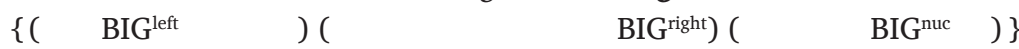
c. Den bruna haren med många söta ungar bor [i PARKEN. $]_{\text {Focus }}$ $\left\{\left(\mathrm{BIG}^{\text {left }}\right)\left(\mathrm{BIG}^{\text {left }}\right)\left(\mathrm{BIG}^{\text {nuc }}\right)\right\}$
d. *Den bruna haren med många söta ungar bor [ i PARKEN. $]_{\text {Focus }}$ $\left\{\left(\mathrm{BIG}^{\text {right }}\right)\left(\mathrm{BIG}^{\text {left }}\right)\left(\mathrm{BIG}^{\text {nuc }}\right)\right\}$

The second part of the argument for a $\varphi$ versus ı distinction relates to the expression of focus. A clause-initial $\varphi$ may be left-headed only if it does not contain an information-structural focus. Prosodic constituents that do contain focus may not be left-headed in Swedish (nor in other Germanic languages, see references in Section 2.2). Thus, among focused subjects with a single big accent, left-headedness is ungrammatical independent of subject length (see Figure 9).

The obligatory right-headedness of constituents that contain focus is accounted for here by the assumptions that a) the focus is obligatorily expressed as an t-head, and b) the $\mathrm{t}$ is obligatorily right-headed..$^{21}$ It is very generally accepted in the literature on West Germanic that the nuclear accent is right-aligned inside a focused constituent, and Swedish behaves very much like other Germanic languages in terms of the distribution of nuclear accents (cf., Myrberg 2010; Myrberg \& Riad 2016 for a longer discussion on the distribution of accents in relation to focus in Swedish and other Germanic languages).

The third part of the argument for distinguishing the categories $\varphi$ and ı consists of the scaling difference between big accents that are the head of an I (nuclear accents) and big accents that are heads of a $\varphi$ (prenuclear accents), presented in Section 4.4.

The fourth part of the argument relates to the existence of an elaborate set of boundary tones at the right edge of the $\mathrm{t}$, which is not present at the right edge of $\varphi$. A thorough review of these boundary tones is beyond the scope of the present article. The interested reader is referred to Myrberg (2010: 99ff) and Myrberg and Riad (2015).

\subsection{The initiality accent and the head hypothesis}

As already mentioned in Sections 1 and 2.3, an important implication of the analysis pursued here is that initiality accents are left-aligned heads of $\varphi$ 's. We may refer to this analysis of the initiality accent as the head hypothesis. While left-headedness at the level of the $\varphi$ is exotic among the Germanic languages, this is arguably the most convincing analysis of the complex patterns of big accent distribution observed here and in previous literature (cf., the previously proposed prominence hypothesis and boundary tone hypothesis summarized below).

21 There are a few special cases where a focus does not contain the nuclear accent, e.g., in sentences with embedded foci or second occurrence focus (Féry \& Samek-Lodovici 2006; Myrberg \& Riad 2016). 
First, the head hypothesis allows the substantial variation in terms of initiality accent distribution that has been observed in this experiment to be captured via the syntax-prosody interface, i.e., via the alignment of $\varphi$ 's with syntactic XP's. If all big accents are heads of $\varphi$, and if the $\varphi$ aligns with the syntactic XP, big accents should exhibit a basic pattern of one big accent per syntactic XP, with exceptions relating e.g., to phrase length and information-structural focus. These predictions regarding the correlation between syntactic XP's and big accents have been shown in Section 4 to be borne out. It is predicted that CP structures should be divided into (at least) two $\varphi$ 's: one containing the preverbal XP, and one containing the rest of the clause (cf., Footnote 16). This is in line with the observation that the preverbal constituent must contain one big accent (head of the $\varphi$ that contains the preverbal constituent) and that there is one more (nuclear) big accent in the VP (head of the constituent that contains the rest of the clause). ${ }^{22}$ Further partitioning of the subject into $\varphi$ 's is predicted to occur e.g., due to complex XP-structures and phrase length, but is not predicted to be obligatory. This is also in accordance with the results.

The prediction that CP-structures are parsed as two $\varphi$ 's seems to be borne out even in very short two- $\omega$ clauses like that in (18) and Figure 19. In Figure 19, a big accent is obligatory at the beginning of the CP (Myrberg 2010: 54-56). The obligatoriness of the double accents in the short (two $\omega$ 's) sentence of Figure 19 is curious from the point of view that subjects of similar length rarely contain two big accents (cf., Figure 9, where it is shown that the two- $\omega$ subjects almost always contain a single big accent). However, the head hypothesis offers the intuitive explanation that the prosodic difference between the two- $\omega$ subject and the two- $\omega$ clause originates in syntax. A two- $\omega$ NP is not parsed as two $\varphi$ 's, whereas a two- $\omega$ clause is parsed as two $\varphi$ 's. It should be noted that in a sentence like that in Figure 19, there will be no way of determining whether the big accent on the first $\omega$ is a left-aligned initiality accent or a right-aligned prenuclear accent, as there is only one possible position for the head to appear in within the $\varphi$. The only sure way of deciding the alignment of a $\varphi$-head, is to look at a constituent that contains at least two $\omega$. We can get some indication but no definite answer to the question by looking at the alignment of the second peak, which regularly but not obligatorily exhibits a later alignment in left-aligned initiality accents than in right-aligned big accents (cf., Figures 1, 2 and 3).

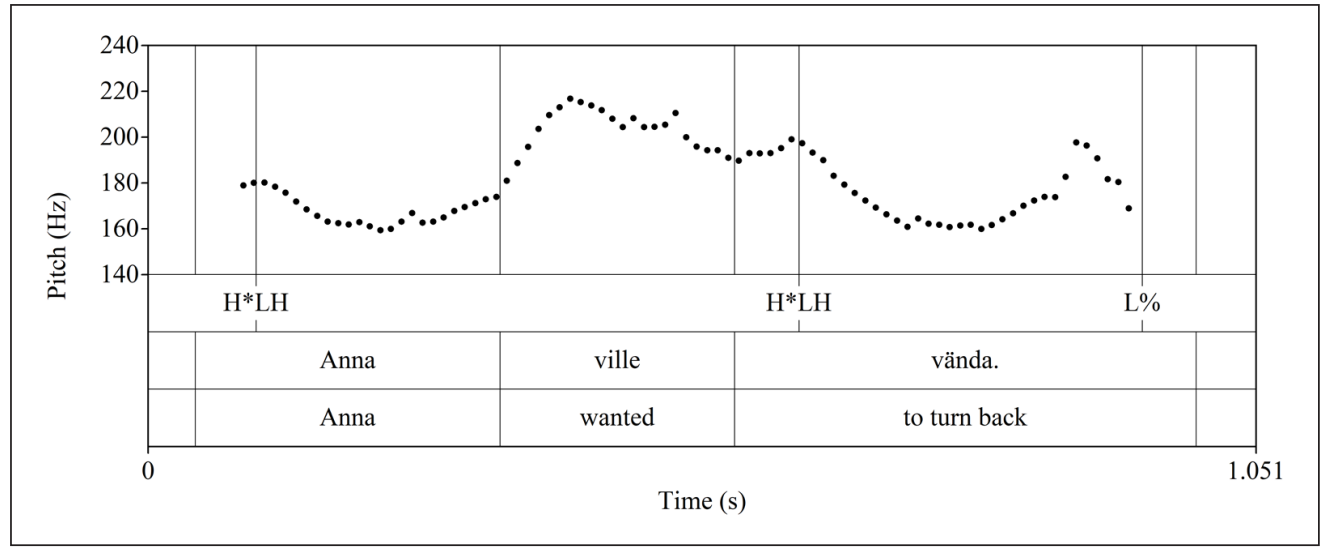

(18) Two-word clause with initiality accent. Round brackets represent $\varphi$-edges. Curly brackets represent t-edges.

a. Vad ville Anna göra?

what wanted Anna do

'What did Anna want to do?'

b. $\begin{array}{lll}{[\text { Anna }} & \text { ville } & \text { VÄNDA. }]_{\text {Focus }} \\ \left\{\left(\mathrm{BIG}^{\mathrm{left}}\right)\right. & \left(\begin{array}{l}\left.\mathrm{BIG}^{\mathrm{nuc}}\right) \\ \text { Anna }\end{array}\right.\end{array}$

'Anna wanted to turn back.'
Figure 19 Initiality accent and nuclear accent in the two- $\omega$ sentence from (18). 
The head analysis also offers a way of understanding why unstressed elements in Spec-CP fail to get initiality accents (Myrberg 2010: 56-57). Specifically, the generalization that the constituent in Spec-CP forms a $\varphi$ holds only for constituents that are able to project their own $\omega$ (cf., the constraint HEADEDNESS from (5), Selkirk 1996). Because unstressed elements like pronouns (e.g., hon 'she', han 'he', den 'it') fail to project a $\omega$, they can also not become the head of any $\varphi$. Instead of forming $\varphi$ 's on their own when in Spec-CP position, they incorporate into a $\omega$ to their right. Thus, in (19b) and Figure 20, vi 'we' incorporates into one $\omega$ together with the verb lämnade 'left'. It remains to be understood why the verb cannot receive an initiality accent in this type of sentence, cf., the ungrammaticality of (19c).

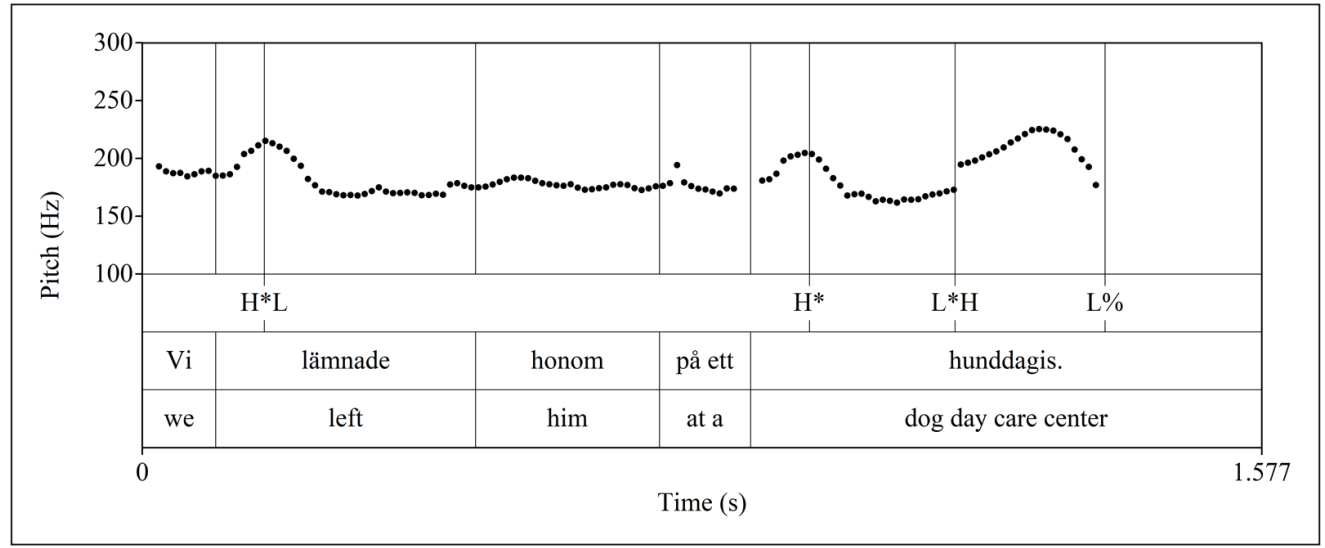

(19) Clauses with a pronoun or another unstressed element in Spec-CP position are not eligible for initiality accent. Round brackets represent $\varphi$-edges. Curly brackets represent t-edges.

a. Vad gjorde ni med hunden när ni åkte på semester? what did you with dog.the when you went on vacation 'What did you do with your dog when you went on vacation?'

b. [ Vi lämnade honom på ett HUNDDAGIS. $]_{\text {Focus }}$ $\left\{\left(\right.\right.$ small accent BIG $\left.\left.^{\text {nuc }}\right)\right\}$ we left him at a dog day care center 'We left him at at dog day care center.'

c. *[ Vi lämnade honom på ett HUNDDAGIS. $]_{\text {Focus }}$ $\left\{\left(\mathrm{BIG}^{\text {left }} \mathrm{BIG}^{\text {nuc }}\right)\right\}$ we left him at a dog day care center 'We left him at at dog day care center.'

The head hypothesis, further, circumvents several problems associated with the two competing analyses. According to the prominence hypothesis (Myrberg 2010), the initiality accent is a type of prominence or pitch accent. However, this "prominence accent" has an unsatisfactorily unclear status in relation to prosodic phrasing, being analysed as a type of pitch accent, yet lacking status as the head of any prosodic category (Myrberg 2010; 2013b).

Under the competing account, the boundary tone hypothesis (Roll 2006; Roll, Horne \& Lindgren 2009), the initiality accent also has a somewhat unclear status, being analysed as a $\mathrm{H} \%$ boundary tone directly associated with the CP node of main clauses. The H\% does not associate with a prosodic edge, however, as would be default for boundary tones. Instead, it appears after the leftmost small accent (tone accent 2: $\mathrm{H}^{*} \mathrm{~L}$, tone accent $1:(\mathrm{H}) \mathrm{L}^{*}$ ), thus rendering a contour similar to that of the big accent (tone accent $2: \mathrm{H}^{*} \mathrm{~L}+\mathrm{H} \%$, tone accent 1 : $(\mathrm{H}) \mathrm{L}^{*}+\mathrm{H} \%$ ). The boundary tone hypothesis, therefore, makes the large similarities between the big accent and the initiality accent look accidental.

Importantly, the boundary tone hypothesis also fails to account for the complex distribution of initiality accents evidenced by the results of the current experiment. The clearest example of this is that the boundary tone hypothesis predicts that the intiality accent should be obligatory at the left edge of CP structures. This prediction is not borne out. A relatively large number of Spec-CP positions contain right-aligned prenuclear accent instead of the left-aligned initiality
Figure $\mathbf{2 0}$ Lack of initiality accent in the sentence from (19b), with an unstressed pronoun in Spec-CP. 
accent (Figure 9), and the initiality accent also fails to appear in clauses where the Spec-CP position contains an unstressed element, (19b). In addition, the boundary tone hypothesis violates the indirect reference hypothesis (Inkelas 1991), as it assumes a direct correlation between syntactic structure (the CP) and prosody (the H\%). Since the advent of the prosodic hierarchy, the indirect reference hypothesis is regarded an important part of phonological theory (cf., e.g., discussions in Nespor \& Vogel 1986; Truckenbrodt 1999) and any violations of it should be well motivated.

Before moving on, a few predictions of the head hypothesis will be outlined. The head hypothesis predicts that only syntactic structures composed of more than one XP are eligible for initiality accent. Because information-structural focus must have an t-head at its right edge (see 5.1), an initiality accent can never project to t-head in any focused constituent or clause. This, in turn, means that the initiality accent can never be the sole big accent in an $\mathrm{t}$, if the $\mathrm{t}$ contains focused information, as most ı's do. A left-headed $\varphi$, then, must always be followed by another right-headed $\varphi$ contained in the same focused constituent and by the same $\mathrm{l}$, which can project to t-head.

This prediction potentially has implications for an issue yet to be empirically studied and theoretically explained. The initiality accent has, by now, been rather well-studied in utterances consisting of clauses, but when it comes to utterances that consist of a noun phrase, like that in (20b), we have much less knowledge. In order to say something about this, an additional recording was made with two speakers of Stockholm Swedish, reading three of the five- $\omega$ subjects from the current experiment in the subject focus context, as in (20). Each subject was repeated twice, rendering a set of twelve sentences. Ten of the twelve noun phrases were read with a single big accent on the last word, as in (20b) and Figure 21. One sentence (both repetitions) was read with two right-aligned accents as in (20c).

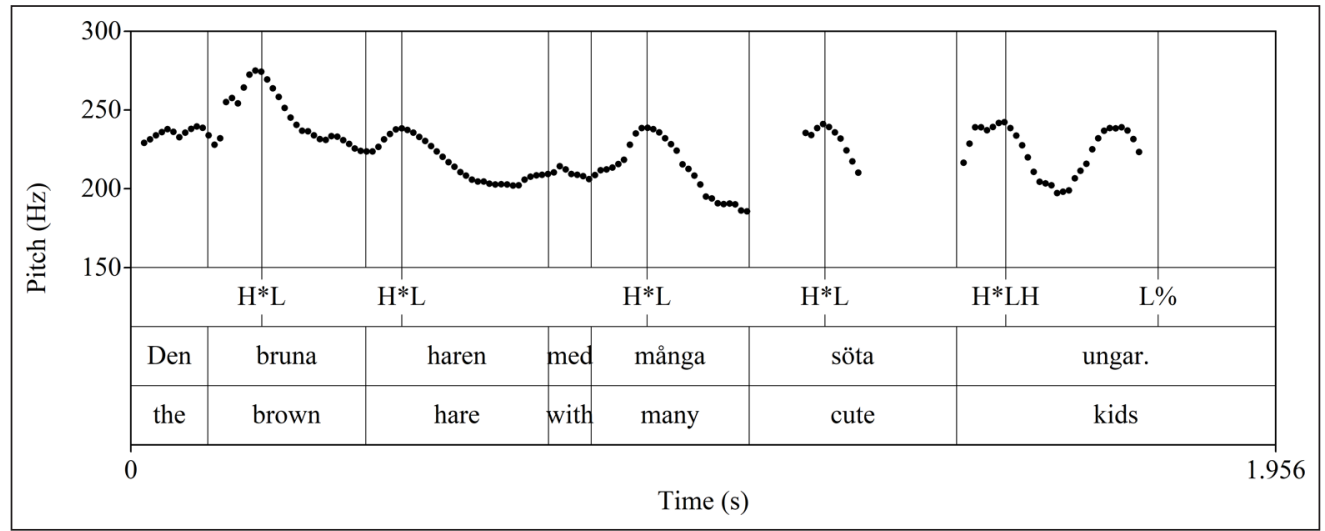

(20)

Prosodic phrasing of NP-utterance.

a. Vilket djur bor på tundran?

what animal lives on tundra.the

'What animal lives on the tundra?'

b. [Den bruna haren med många söta UNGAR. $]_{\text {Focus }}$ $\left\{\left(\mathrm{BIG}^{\text {nuc }}\right)\right\}$

the brown hare with many cute kids

'The brown hare with many cute kids.'

c. [Den bruna haren) ( med många söta UNGAR. $]_{\text {Focus }}$

$\left\{\left(\mathrm{BIG}^{\text {right }}\right)\left(\mathrm{BIG}^{\text {nuc }}\right)\right\}$

the brown hare with many cute kids

'The brown hare with many cute kids.'

This small data set suggests that initiality accents are not common, and possibly not allowed, in utterances consisting of a noun phrase. If true, this distinguishes noun phrase utterances from clause utterances. One prediction of the head analysis is that only noun phrases that are phrased as more than one $\varphi$ should be eligible for initiality accent (to the extent that NP utterances ever receive an initiality accent). Future research must determine whether noun phrases may have a left-aligned $\varphi$-head, and if so, under what conditions.
Figure 21 Lack of initiality accent in noun phrase utterance, cf., (20b). 


\subsection{Final accenting: Additional evidence for $\varphi$-break after Spec-CP}

As previously discussed, the analysis pursued in this article implies that it is ungrammatical for a non-pronominal preverbal subject to be contained in the same prosodic phrase as the rest of the clause, i.e., that the constituent in Spec-CP obligatorily forms a $\varphi$. The main argument for this is the unacceptability of (16c). In this section, I discuss some data, yet to be experimentally tested, which provide additional indications that there is a prosodic edge at the right edge of Spec-CP. It can be noted that the patterns described in this section are reminiscent of patterns reported from English (e.g., Selkirk 1996; Itô \& Mester 2019a).

Some words are deaccented in non-final positions. This applies especially to some groups of verbs, as illustrated in (21a) with auxiliary verbs and in (21b) with the verb går 'goes'. ${ }^{23}$ Verbs and other words that fail to receive a small or big accent do not form maximal $\omega$ on their own, but incorporate across the $\omega$-edge into the $\omega$ to their right, as in (21). ${ }^{24}$ There is, to date, no exact description of which words or verbs may be deaccented or why, but see e.g., Myrberg \& Riad (2015) for discussion.

Auxiliaries like vill/kan 'want/can' in a, and some other light verbs, like går 'goes' in $\mathrm{b}$ are deaccented and incorporate into a $\omega$ to their right. Recall from Section 2 that $\omega$ throughout this article refers to the maximal prosodic word, which contains one small or big accent (but may contain multiple lexically stressed syllables). See Myrberg \& Riad (2015).

$$
\begin{aligned}
& \text { a. (Anna ) })_{\omega \omega}(\text { vill/kan SPRINGA. })_{\omega} \\
& \left.{ }_{{ }_{1}}^{\infty}\left(\mathrm{BIG}^{\text {left }}\right)_{\varphi}{ }_{\varphi}(\mathrm{BIG})_{\varphi}^{\text {nuc }}\right\}_{\text {, }} \\
& \text { Anna wants/can run }
\end{aligned}
$$

'Anna wants to/can run.'
b. $\omega_{\omega}(\text { Projektet })_{\omega \omega}(\text { går BRA. ) })_{\omega}$
$\left\{_{\varphi}\left(B^{\text {BIft }} \quad\right)_{\varphi \varphi}\left(\quad \text { BIG }^{\text {nuc }}\right)_{\varphi}\right\}_{\text {, }}$ project.the goes well

'The project is running well.'

When otherwise deaccented words as in (21) appear rightmost in an t, they are obligatorily accented, as illustrated in (22).

23 Many verbs also vacillate between accented vs. deaccented, like planera 'plan', which seems more likely to be accented in (ii) than in (i). Presumably, the type of complement would play a role in (i) vs. (ii). However, there are also verbs that appear to resist deaccenting entirely, like varnar 'warns' in (iii). Which verbs allow deaccenting and under what conditions is an empirical domain yet to be explored.

(i)

$$
\begin{aligned}
& { }_{\omega}\left(\text { Olle }{ }_{\omega}{ }_{\omega} \text { (planerar en fest.) }{ }_{\omega}\right. \\
& \text { Olle plans a party } \\
& \text { 'Olle is planning a party.' }
\end{aligned}
$$

(ii) $\omega_{\omega}(\text { Olle })_{\omega} \omega_{\omega}$ (planerar) $\omega_{\omega} \omega_{\omega}$ (höstens $)_{\omega} \omega_{\omega}$ (schema. $)_{\omega}$

Olle plans fall's schedule

'Olle is planning the schedule for the fall semester.'

(iii) $\omega_{\omega}(\text { Föraren })_{\omega} \omega_{\omega}$ (varnar) $)_{\omega}$ (resenärerna.) $\omega_{\omega}$

driver.the warns travelers.the

'The driver is warning the travelers'

In addition to verbs, unstressed words, including many pronouns and prepositions, frequently appear deaccented. Likewise, all but the last word of lexicalized phrases are deaccented due to incorporation, e.g., the lexicalized phrase in (i). Riad (2014) and Myrberg \& Riad (2015) analyze this type of deaccenting in terms of recursion of the $\omega$.

(iv)

$$
\begin{aligned}
& \left.{ }_{\omega}^{(}{ }_{\omega}(\text { röda })_{\omega}{ }_{\omega}(\text { hund })_{\omega}\right)_{\omega} \\
& \text { red } \operatorname{dog} \\
& \text { 'Rubella/German measles' }
\end{aligned}
$$

24 Incorporation to the left is limited in Swedish and is ruled out in the cases discussed here. Cf., Myrberg \& Riad (2015). 
In t-final position, otherwise deaccented verbs obligatorily receive an accent. Importantly, in the sentences below, there is a narrow focus early in the sentence. Nonetheless, an obligatory small accent appears on the sentence final verbs vill/kan 'want/can' in a and garr 'goes' in b. Recall from Section 2 that $\omega$ throughout this article refers to the maximal prosodic word, which contains one small or big accent (but may contain multiple lexically stressed syllables). See Myrberg \& Riad (2015).

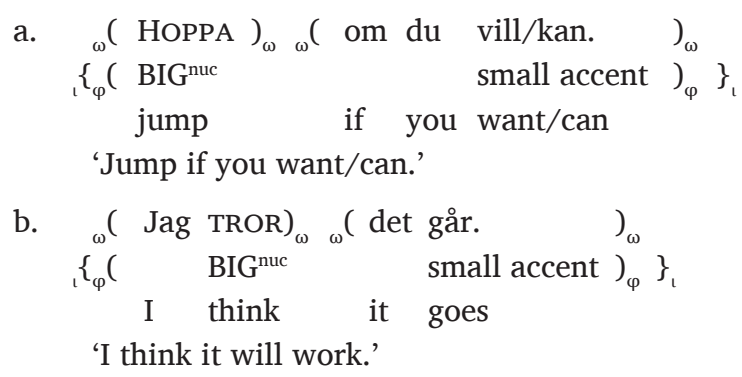

Interestingly, the verbs in (21)-(22) are also obligatorily accented (big or small accent) when they appear rightmost in Spec-CP. This is illustrated in (23a) and (23b). This fact constitutes additional evidence for an obligatory prosodic edge at the right edge of Spec-CP.

Otherwise deaccented verbs receive an obligatory accent (big or small) when they appear finally in the Spec-CP-position. Recall from Section 2 that $\omega$ throughout this article refers to the maximal prosodic word, which contains one small or big accent (but may contain multiple lexically stressed syllables). See Myrberg \& Riad (2015).

a

$$
\begin{aligned}
& \text { - (Om det går ) } \left.)_{\omega}(\text { ska du skicka })_{\omega \omega} \text { (den med POST. }\right)_{\omega} \\
& { }_{i}{ }_{\varphi}\left(\mathrm{BIG}^{\mathrm{right}}\right)_{\varphi}\left(\text { small accent }_{\varphi}\left(\mathrm{BIG}^{\mathrm{nuc}}\right)_{\varphi}\right\}_{\text {, }} \\
& \text { if it works should you send it by post }
\end{aligned}
$$

'If possible, you should send it by post.'

b. ${ }_{\omega}(\text { Om Anna })_{\omega}(\text { vill })_{\omega} \omega_{\omega}(\text { kan jag HJÄLPA henne. })_{\omega}$

$\left.\begin{array}{lllllll}\left\{_{\varphi}^{\omega}(\right. & \mathrm{BIG}^{\text {left }} & \text { small accent })_{\varphi}{ }_{\varphi}( & & \mathrm{BIG}^{\mathrm{nuc}} & & )_{\varphi}\end{array}\right\}_{1}$

'If Anna wants, I can help her.'

\section{Summary and conclusion}

This article has reported the results of a production experiment where five speakers of Stockholm Swedish read 1200 sentences with NP subjects in clause-initial position. The NP subjects consisted of two, three, four or five $\omega$ 's and focus was located either inside the subject or inside the verb phrase.

The experiment was designed to reveal the behavior of the so-called big accent in Stockholm Swedish, to generate a better understanding of this typologically uncommon phenomenon. The results have been argued to show that all big accents are heads of a $\varphi$, and that the rightmost $\varphi$-head projects to become the head of $\mathrm{t}$, the nuclear accent. The nuclear accent has (in principle) a one-to-one correlation with information-structural focus, whereas prenuclear accents, i.e., big accents that appear to the left of the nuclear accent, lack any correlation with focus.

The results show that a large amount of variation is possible in terms of the prosodic phrasing, but that the constituent in Spec-CP obligatorily forms a $\varphi$ separate from the rest of the clause. This $\varphi$ is identified via an obligatory big accent inside the Spec-CP constitutent (Section 4), as well as obligatory accenting (big or small) at the right edge of the Spec-CP (Section 5.3).

In order to account for the large variation in the distribution of big accents, the so-called initiality accent (Myrberg 2010; 2013) is analysed here as a head of $\varphi$. This means that prenuclear big accents may be aligned with the left or the right edge of the $\varphi$. Left-aligned heads are referred to as initiality accents, whereas right-alignment may be seen as the default location of the head in $\varphi$. This assumption regarding the phonological nature of the initiality accent is referred to as the head hypothesis. The head hypothesis offers several advantages over the previously proposed hypotheses (the prominence hypothesis by Myrberg 2010 and the boundary tone hypothesis by Roll, Horne \& Lindgren 2009). Most importantly, the head hypothesis is compatible with the large amount of optionality in terms of the distribution of initiality accents and other big accents, which is evidenced by the current experiment. 


\section{Additional File}

The additional file for this article can be found as follows:

- Appendix. Appendices A and B. DOI: https://doi.org/10.5334/gigl.1227.s1

\section{Acknowledgements}

I am indebted to several people for insightful discussions, and for pointing out mistakes in earlier versions of the text. I want to mention especially Tomas Riad, Shinichiro Ishihara, Caroline Féry, the members of the Phonology seminar in Lund, and two anonymous reviewers. Any remaining mistakes are entirely my own. I gratefully acknowledge financial support from Anna Ahlströms och Ellen Terserus stiftelse, and from the Swedish Research Council (grant number 2016-01536).

\section{Competing interests}

The author has no competing interests to declare.

\section{Author affiliation}

Sara Myrberg (D) orcid.org/0000-0002-9469-6058

Centre for Languages and Literature, SOL, Lund University, SE-221 00 Lund, GB

\section{References}

Ambrazaitis, Gilbert. 2009. Nuclear intonation in Swedish: Evidence from experimental-phonetic studies and a comparison with German. Lund: Lund University dissertation.

Bennett, Ryan, Emily Elfner \& James McCloskey. 2016. Lightest to the Right: An apparently anomalous displacement in Irish. Linguistic Inquiry 47(2). 169-234. https://doi-org.ludwig.lub.lu.se/10.1162/ LING_a_00209. DOI: https://doi.org/10.1162/LING_a_00209

Bennett, Ryan, Emily Elfner \& James McCloskey. 2019. Prosody, focus, and ellipsis in Irish. Language 95(1). 66-106. https://doi-org.ludwig.lub.lu.se/10.1353/lan.2019.0012. DOI: https://doi.org/10.1353/ lan.2019.0012

Boersma, Paul \& David Weenink. 2016. Praat: doing phonetics by computer http://www.praat.org/. Bruce, Gösta. 1977. Swedish word accents in sentence perspective. Lund: LiberLäromedel/Gleerup.

Bruce, Gösta. 1982. Developing the Swedish intonation model. Working papers 22, 51-116. Lund: Department of Linguistics and Phonetics, Lund University.

Bruce, Gösta. 1987. How Floating is Focal Accent? In Kirsten Gregersen \& Hans Basbøll (eds.), Nordic Prosody 4, 41-49. Odense University Press.

Bruce, Gösta. 1998. Allmän och svensk prosodi [General and Swedish prosody]. Lund: Lund University, Department of Linguistics.

Bruce, Gösta. 2005. Intonational prominence in Swedish revisited. In Sun-Ah Jun (ed.), Prosodic typology: The phonology of intonation and phrasing, 410-429. Oxford: Oxford University Press. DOI: https://doi. org/10.1093/acprof:oso/9780199249633.001.0001

Bruce, Gösta. 2007. Components of a prosodic typology of Swedish intonation. In Tomas Riad \& Carlos Gussenhoven (eds.), Tones and tunes, Volume I: Typological studies in word and sentence prosody, 114-145. Berlin: de Gruyter Mouton. https://doi-org.ludwig.lub.lu.se/10.1515/9783110207569. DOI: https://doi.org/10.1515/9783110207569.113

Bruce, Gösta. 2010. Vår fonetiska geografi: Om svenskans accenter, melodi och uttal [Our phonetic geography: About accents, melody and pronounciation of Swedish]. Lund: Studentlitteratur.

Bruce, Gösta, Björn Granström, Kjell Gustafson \& David House. 1993. Interaction of F0 and duration in the perception of prosodic phrasing in Swedish. In Björn Granström \& Lennart Nord (eds.), Nordic Prosody VI: Papers from a symposium, 7-22. Stockholm: Almqvist \& Wiksell International.

Elfner, Emily. 2015. Recursion in prosodic phrasing: Evidence from Connemara Irish. Natural Language \& Linguistic Theory 33(4). 1169-1208. DOI: https://doi.org/10.1007/s11049-014-9281-5

Elordieta, Gorka. 2007. A constraint-based analysis of the intonational realization of focus in Northern Bizkaian Basque. In Tomas Riad \& Carlos Gussenhoven (eds.), Tones and Tunes, Volume I: Typological Studies in Word and Sentence Prosody, 199-232. Berlin: Mouton de Gruyter. DOI: https://doi-org. ludwig.lub.lu.se/10.1515/9783110207569

Elordieta, Gorka. 2015. Recursive phonological phrasing in Basque. Phonology 32(1). 49-78. DOI: https:// doi.org/10.1017/S0952675715000044 
Feldhausen, Ingo. 2010. Sentential form and prosodic structure of Catalan. Amsterdam, Philadelphia: John Benjamins Publishing Company. DOI: https://doi.org/10.1075/la.168

Feldhausen, Ingo. 2016. Inter-speaker variation, Optimality Theory, and the prosody of clitic leftdislocations in Spanish. Probus: International Journal of Latin \& Romance Linguistics 28(2). $293-333$. DOI: https://doi.org/10.1515/probus-2015-0005

Féry, Caroline. 1993. German intonational patterns. Tübingen: Niemeyer. DOI: https://doi.org/10.1515/978 3111677606

Féry, Caroline. 2013. Focus as prosodic alignment. Natural Language \& Linguistic Theory 31(3). 683-734. DOI: https://doi.org/10.1007/s11049-013-9195-7

Féry, Caroline \& Vieri Samek-Lodovici. 2006. Focus Projection and Prosodic Prominence in Nested Foci. Language 82(1). 131-150. DOI: https://doi.org/10.1353/lan.2006.0031

Gussenhoven, Carlos. 2004. Phonology of Tone and Intonation. Cambridge: Cambridge University Press. DOI: https://doi.org/10.1017/CBO9780511616983

Gussenhoven, Carlos \& Gösta Bruce. 1999. Word prosody and intonation. In Harry van der Hulst (ed.), Word Prosodic Systems in the Languages of Europe, 233-271. Berlin: Mouton de Gruyter.

Hamlaoui, Fatima \& Kriszta Szendrői. 2017. The syntax-phonology mapping of intonational phrases in complex sentences: A flexible approach. Glossa 2(1). DOI: https://doi.org/10.5334/gigl.215

Hansson, Petra. 2003. Prosodic phrasing in spontaneous Swedish. Lund: Lund University dissertation.

Heldner, Mattias. 2001. Focal accent - $f_{0}$ movements and beyond. Umeå: Umeå University dissertation.

Horne, Merle. 1994. Generating prosodic structure for synthesis of Swedish intonation, Working Papers 43, 72-75. Lund: Department of Linguistics, Lund University.

Inkelas, Sharon. 1991. Prosodic constituency in the lexicon. London: Routledge. DOI: https://doi. org/10.4324/9780429455209

Ishihara, Shinichiro. 2014. Match Theory and the Recursivity Problem. In Shigeto Kawahara \& Mika Igarashi (eds.), FAJL 7: Formal Approaches to Japanese Linguistics, 69-88. MIT: Department of Linguistics and Philosophy.

Ishihara, Shinichiro. 2015. Syntax-phonology interface. In Haruo Kubozono (ed.), Handbook of Japanese Phonetics and Phonology, 569-618. New York: de Gruyter Mouton. DOI: https://doi. org/10.1515/9781614511984

Itô, Junko \& Armin Mester. 2007. Prosodic adjunction in Japanese Compounds. MIT Working Papers in Linguistics 55: Formal Approaches to Japanese Linguistics 4, 97-111. Cambridge, Massachusetts.

Itô, Junko \& Armin Mester. 2012. Recursive prosodic phrasing in Japanese. In Toni Borowsky, Shigeto Kawahara, Mariko Sugahara \& Takahito Shinya (eds.), Prosody matters: Essays in honor of Elisabeth Selkirk, 280-303. London: Equinox.

Itô, Junko \& Armin Mester. 2019a. Match as syntax-prosody Max/Dep: Prosodic Enclisis in English. English Linguistics 36(1). 1-28.

Itô, Junko \& Armin Mester. 2019b. Match Theory and Prosodic Well formedness constraints. In Hongming Zhang \& Youyong Quian (eds.), Prosodic Studies: Challenges and prospects, 252-274. London: Routledge. DOI: https://doi.org/10.4324/9781351212878-10

Kalivoda, Nicholas. 2018. Syntax-Prosody Mismatches in Optimality Theory. California: University of California Santa Cruz dissertation.

Ladd, D. Robert. 2008. Intonational phonology 2 ed. New York: Cambridge University Press. DOI: https:// doi.org/10.1017/CBO9780511808814

McCarthy, John \& Alan Prince. 1993. Generalized alignment. Yearbook of Morphology 1993, 79-153. DOI: https://doi.org/10.1007/978-94-017-3712-8_4

Myrberg, Sara. 2010. The intonational phonology of Stockholm Swedish. Stockholm: Stockholm University dissertation.

Myrberg, Sara. 2013a. Focus type effects on focal accents and boundary tones. In Robert Eklund (ed.), Fonetik 2013, 53-56. Sweden: Linköping University.

Myrberg, Sara. 2013b. Sisterhood in prosodic branching. Phonology 30(1). 73-124. DOI: https://doi. org/10.1017/S0952675713000043

Myrberg, Sara. 2019. Big accent distribution in Stockholm Swedish. Paper presented at the SPOT (SyntaxProsody in Optimality Theory) Workshop, University of California Santa Cruz.

Myrberg, Sara \& Tomas Riad. 2015. The prosodic hierarchy of Swedish. Nordic Journal of Linguistics 38(2). 115-147. DOI: https://doi.org/10.1017/S0332586515000177

Myrberg, Sara \& Tomas Riad. 2016. On the expression of focus in the metrical grid and in the prosodic hierarchy. In Caroline Féry \& Shinichiro Ishihara (eds.), The Oxford Handbook of Information Structure, 441-462. Oxford: Oxford University Press. DOI: https://doi.org/10.1093/ oxfordhb/9780199642670.013.41

Nespor, Marina \& Irene Vogel. 1986. Prosodic phonology. Dordrecht: Foris.

Pierrehumbert, Janet. 1980. The phonology and phonetics of English intonation. Massachusetts: Massachusetts Institute of Technology dissertation. 
Prince, Alan \& Paul Smolensky. 1993. Optimality Theory: Constraint interaction in generative grammar. Ms, Rutgers University \& University of Colorado at Boulder. Published 2004, Malden, MA \& Oxford: Blackwell.

Riad, Tomas. 1998. Towards a Scandinavian tone accent typology. In Wolfgang Kehrein \& Richard Wiese (eds.), Phonology and morphology of the Germanic languages, 77-109. Tübingen: Niemeyer. DOI: https://doi.org/10.1515/9783110919769.77

Riad, Tomas. 2006. Scandinavian accent typology. In Åke Viberg (ed.), Special issue on Swedish. Sprachtypologie und Universalienforschung (STUF), 36-55.

Riad, Tomas. 2012. Culminativity, stress and tone accent in Central Swedish. Lingua 122(13). 1352-1379. DOI: https://doi.org/10.1016/j.lingua.2012.07.001

Riad, Tomas. 2014. The phonology of Swedish. Oxford: Oxford University Press. DOI: https://doi. org/10.1093/acprof:oso/9780199543571.001.0001

Riad, Tomas. 2015. Prosodin i svenskans morfologi. Stockholm: Morfem.

Roll, Mikael. 2006. Prosodic cues to the syntactic structure of subordinate clauses in Swedish. In Gösta Bruce \& Merle Horne (eds.), Nordic Prosody IX, Lund, 2004, 195-204. Frankfurt am Main: Peter Lang.

Roll, Mikael, Merle Horne \& Magnus Lindgren. 2009. Left-edge boundary tone and main clause verb effects on syntactic processing in embedded clauses: An ERP study. Journal of neurolinguistics 22(1). 55-73. DOI: https://doi.org/10.1016/j.jneuroling.2008.06.001

Selkirk, Elisabeth. 1984. Phonology and syntax: The relation between sound and structure. Cambridge, Mass.: MIT Press.

Selkirk, Elisabeth. 1995. Sentence prosody: Intonation, stress, and phrasing. In John A. Goldsmith (ed.), The handbook of phonological theory, 550-569. Oxford: Blackwell.

Selkirk, Elisabeth. 1996. The prosodic structure of function words. In James L. Morgan \& Katherine Demuth (eds.), Signal to syntax: Bootstrapping from speech to grammar in early acquisition, 187-214. Mahwah, NJ: Erlbaum.

Selkirk, Elisabeth. 2011. The syntax-phonology interface. In John A. Goldsmith, Jason Riggle \& Alan Yu (eds.), The handbook of phonological theory, 2nd edition, 435-484. Oxford: Blackwell. DOI: https://doi. org/10.1002/9781444343069.ch14

Strangert, Eva \& Mattias Heldner. 1995a. Labelling of boundaries and prominences by phonetically experienced and non-experienced transcribers, PHONUM 3, 85-109. Umeå: Department of Phonetics, Umeå University.

Strangert, Eva \& Mattias Heldner. 1995b. The labelling of prominence in Swedish by phonetically experienced transcribers, Proceedings ICPhS 95, 204-207. Stockholm: Department of Speech Communication and Music Acoustics, KTH and Department of Linguistics, Stockholm University.

Söderström, Pelle. 2017. Prosody and prediction in Neural Speech Processing. Lund: Lund University dissertation.

Truckenbrodt, Hubert. 1995. Phonological phrases: Their relation to syntax, focus, and prominence. Massachusetts: Massachusetts Institute of Technology dissertation.

Truckenbrodt, Hubert. 1999. On the Relation between Syntactic Phrases and Phonological Phrases. Linguistic Inquiry 30(2). 219-255. DOI: https://doi.org/10.1162/002438999554048
TO CITE THIS ARTICLE: Myrberg, Sara. 2021. Big accents in Stockholm Swedish: Nuclear accents, prenuclear accents, and initiality accents. Glossa: a journal of general linguistics 6(1): 81. 1-28. DOI: https://doi.org/10.5334/ gjgl.1227

Submitted: 20 February 2020 Accepted: 17 September 2020 Published: 29 June 2021

\section{COPYRIGHT:}

(C) 2021 The Author(s). This is an open-access article distributed under the terms of the Creative Commons Attribution 4.0 International License (CC-BY 4.0), which permits unrestricted use, distribution, and reproduction in any medium, provided the original author and source are credited. See http:// creativecommons.org/ licenses/by/4.0/.

Glossa: a journal of general linguistics is a peer-reviewed open access journal published by Ubiquity Press. 